\title{
Principal component analysis of MSBAS DInSAR time series from Campi
}

\section{Flegrei, Italy}

4 Kristy F. Tiampo ${ }^{1}$, Pablo J. Gonzalez ${ }^{2}$, Sergey Samsonov ${ }^{3}$, Jose Fernández ${ }^{4}$, Antonio Camacho ${ }^{4}$

$5{ }^{1}$ Cooperative Institute for Research in Environmental Sciences (CIRES), University of Colorado

6 at Boulder, USA

$7 \quad{ }^{2}$ Department of Earth, Ocean and Ecological Sciences, University of Liverpool, UK

$8{ }^{3}$ Canada Centre for Mapping and Earth Observation, Natural Resources Canada, Ottawa,

9 Ontario, Canada

$10{ }^{4}$ Institute of Geosciences (CSIC-UCM), Madrid, Spain

RUNNING TITLE: PCA analysis of MSBAS data, Campi Flegrei, Italy

Key words: Campi Flegrei, geodesy, principal component analysis, Interferometric Synthetic Aperture Radar, DInSAR, Multidimensional Small Baseline Subset, MSBAS within its caldera, Campi Flegrei is one of the highest risk volcanic areas in the world. Since the

21 last major eruption in 1538, the caldera has undergone frequent episodes of ground subsidence and uplift accompanied by seismic activity that has been interpreted as the result of a stationary, deeper source below the caldera that feeds shallower eruptions. However, the location and depth of the deeper source is not well-characterized and its relationship to current activity is poorly 
27 Here we apply a principal component decomposition to high resolution time series from the

28 region produced by the advanced Multidimensional SBAS DInSAR technique in order to better

29 delineate both the deeper source and the recent shallow activity. We analyzed both a period of 30 substantial subsidence (1993-1999) and a second of significant uplift (2007-2013) and inverted

31 the associated vertical surface displacement for the most likely source models. Results suggest

32 that the underlying dynamics of the caldera changed in the late 1990s, from one in which the

33 primary signal arises from a shallow deflating source above a deeper, expanding source to one

34 dominated by a shallow inflating source. In general, the shallow source lies between 2700 and

$353400 \mathrm{~m}$ below the caldera while the deeper source lies at $7600 \mathrm{~m}$ or more in depth. The

36 combination of principal component analysis with high resolution MSBAS time series data

37 allows for these new insights and confirms the applicability of both to areas at risk from dynamic

38 natural hazards.

\section{Introduction}

40

41

42

43

44

45

46

47

48

49

50
A significant portion of the city of Naples lies within the Campi Flegrei caldera, along with the town of Pozzuoli and a number of densely inhabited villages, making it one of the most dangerous volcanic areas on Earth (Orsi et al., 2004; De Natale et al., 2006; Isaia et al., 2009). The last major eruption occurred at Monte Nuovo in 1538, following a period of ground uplift which interrupted a period of secular subsidence that has persisted for centuries. During that time, Campi Flegrei has undergone frequent episodes of ground subsidence and uplift accompanied by seismic activity (Troise et al., 2007). Most recently, in June of 2010 moderate uplift rates were observed that substantially increased in 2011 and further accelerated in 2012. Between 2010 and 2013, maximum uplift reached approximately $13 \mathrm{~cm}$, as identified by differential Interferometric Synthetic Aperture Radar (DInSAR) (Samsonov et al., 2014). 
52 DInSAR is used extensively today for mapping ground deformation with high spatial resolution

53 and sub-centimeter precision over large areas, and is a suitable tool for deformation monitoring

54 of active volcanic areas (Massonnet and Feigl, 1998; Rosen et al., 2000; Wadge, 2003;

55 Fernández et al., 2009). A radar interferogram is calculated from two SAR images with identical

56 characteristics acquired by space- and/or air-borne sensors at two different times and captures the

57 intervening deformation. Spatial resolution of modern SAR sensors ranges from 1 to $20 \mathrm{~m}$ over

58 areas from $10 \times 10 \mathrm{~km}$ to $200 \times 200 \mathrm{~km}$. For modern satellite constellations the repeat cycle ranges

59 from a few days to a few weeks, with the typical repeat cycle for a single satellite mission at 24 to 41 days. Repeatedly acquired SAR data from a single sensor can be used to obtain line-of-

61 sight (LOS) time series analysis of surface displacement through the application of either Small

62 Baseline Subset (SBAS) (Berardino et al., 2002; Usai, 2003; Samsonov et al., 2011), Persistent

63 Scatterers (PS) (Ferretti et al., 2001) methods or their combination (Hooper, 2008). The results

64 are limited to the time period of the individual data set and do not automatically distinguish

65 between horizontal and vertical motion.

66 The Multidimensional SBAS (MSBAS) technique (Samsonov and d'Oreye, 2012) combines

67 multiple DInSAR data sets into a single solution. Improved characteristics include lower noise

68 and improved temporal resolution with almost uninterrupted temporal coverage. The MSBAS

69 methodology is an extension of the original SBAS method. MSBAS addresses the data

70 redundancy and multidimensionality of the problem by decomposing LOS DInSAR

71 measurements into the vertical and horizontal (east-west) time series of surface deformation

72 using ascending and descending DInSAR data. MSBAS recently has been applied to the

73 mapping of anthropogenic (Samsonov et al., 2013, 2014a) and natural (Samsonov and d'Oreye, 
74 2012; Samsonov et al., 2014b) ground deformation, successfully producing two-dimensional

75 time series with dense temporal resolution and high precision.

76 In this study we apply a principal component decomposition technique to an MSBAS DInSAR

77 time series of more than twenty years, produced from ERS-1/2, ENVISAT and RADARSAT-2

78 data at Campi Flegrei, Italy (Figure 1) (Samsonov et al., 2014b). Various versions of principal

79 component analysis (PCA) filtering techniques have been developed and applied over the past 28

80 years with the goal of reducing or removing the various noise sources in the position time series.

81 For example, in the first successful geodetic application, Savage (1988) decomposed

82 displacements at Long Valley caldera into the predominant modes in order to study only the

83 signal that accounted for the greatest percentage of the variance, the volcanic source below the

84 dome. In addition, he identified the primary error sources in the data using the remaining

85 eigenmodes. Tiampo et al. (2004) employed a Karhunen-Loeve expansion (KLE) analysis to

86 study spatiotemporally correlated mass loading caused by seasonal deformation in Southern

87 California Integrated GPS Network (SCIGN) position series data. Dong et al. (2006) later

88 employed common mode error (CME) filtering using both PCA and KLE techniques in order to

89 identify signal and systematic error in regional GPS position time series. Zerbini et al. (2010)

90 applied a similar technique to GPS and gravity data in northeastern Italy and succeeded in

91 identifying hydrology-related correlated variations, while Chaussard et al. (2014) used a PCA

92 decomposition of DInSAR data to study aquifer changes in northern California. Here, because

93 the MSBAS data produces a time series with unprecedented duration and resolution for this

94 region, the PCA produces individual spatial and temporal modes at high resolution in both space

95 and time. Various combinations of the resulting eigenmodes are inverted using a genetic

96 algorithm (GA) inversion technique and a combination of simple spherical pressure models 
97 (Mogi, 1958). The combination of these three techniques - MSBAS DInSAR, PCA

98 decomposition and GA inversion - results in the improved characterization of the two separate

99 sources below Campi Flegrei and new insights into the interactions between the deeper source

100 and the recent shallow activity. Results suggest that the underlying dynamics of the caldera

101 changed in the late 1990s, from one in which the primary signal arises from a shallow deflating

102 source above a deeper, expanding source to one dominated by a shallow inflating source.

103 In Section 2 we provide an overview of historic activity at Campi Flegrei. Section 3 provides

104 details on the MSBAS technique and the SAR data used in this study. Section 4 describes the

105 PCA technique and the resulting decomposition of the MSBAS time series into their eigenmodes

106 and principal components. The GA inversion technique and its application to the significant

107 eigenmodes are detailed in Section 5. The last section discusses the results and implications of

108 this analysis for constraining different geophysical sources at Campi Flegrei.

109

110

111

112

113

114

115

116

117 eruptions for the last $5 \mathrm{ka}$.

118 The most recent uplift probably began in 1950 and included two major periods of seismic unrest

119 in 1969-1972 and 1982-1984, before reaching a maximum value of about $3.5 \mathrm{~m}$ in 1985

120 (Gottsman et al., 2006a; Del Gaudio et al., 2010; D’Auria et al., 2011). Since 1988, slow 
121 deflation intermittently has been interrupted by periods of seismic swarms and minor uplift, until

122 the mid-2000s (Trasatti et al., 2015). At that time, a significant increase in the uplift rate took

123 place, resulting in almost 13 meters of uplift by 2013 (De Martino et al., 2014; Samsonov et al., 124 2014b).

125

126 FIGURE1

127

128 Between 1981 and 2001, surveys at Campi Flegrei revealed significant gravity changes.

129 Interpretation, in conjunction with deformation data, suggested that the phenomena are the result 130 of changes in the caldera hydrothermal systems (Bonafede \& Mazzanti, 1998), activity within 131 the subsurface magmatic reservoir (Dvorak \& Berrino, 1991; Fernández et al., 2001), or some 132 combination of the two (Gottsmann et al., 2005, 2006). Recent petrological and geochemical 133 studies suggest that there are two magmatic sources that differ in composition, depth and size, 134 and that the periodic episodes of uplift and unrest are the result of reinjection of $\mathrm{CO}_{2}$-rich fluids 135 and magma (Caliro et al., 2007; Arienzo et al., 2010; Mormone et al., 2011; D’Auria et al., 2011, 136 2012; Moretti et al., 2013; Amoruso et al., 2014a; Trasatti et al., 2015).

137 Over the years, a number of different models have been ascribed to the shallow source, or 138 sources, at Campi Flegrei. These generally include a primary inflation source between $2-4 \mathrm{~km}$ in 139 depth below the caldera and some combination of shallower hydrothermal sources near the 140 Solfatara crater (De Natale et al. 1991, De Natale et al., 2006; Gottsmann et al., 2005, 2006;

141 Amoruso et al., 2008; Trasatti et al., 2011; Amoruso et al., 2014a; Samsonov et al., 2014b;

142 Trasatti et al., 2015, among others), although some studies have attributed CF activity primarily 143 to fluid injection in the hydrothermal system (Battaglia et al., 2006; Troiano et al., 2011). 
144 Battaglia et al. (2006) inverted levelling, trilateration and gravity from the period between 1980

145 and 1995 and found that the inflation period during the 1980s was the result of a penny-shaped

146 crack at a depth of approximately $3 \mathrm{~km}$ and the subsequent deflation was generated by a source

147 shaped like a prolate spheroid at a depth between 1.9 and $2.2 \mathrm{~km}$ deep. More recently, Amoruso

148 et al. (2015) modeled observed strain changes from March of 2010 as the result of volume

149 changes in an offshore, slightly deeper ellipsoidal magma source at approximately $3200 \mathrm{~m}$ depth.

150 Tomographic studies suggest that there is a high $\mathrm{Vp} / \mathrm{Vs}$ ratio at shallow depths, indicating

151 infiltration by hydrothermal fluids (Chiarabba and Moretti, 2006; Zollo et al., 2008). Seismic

152 attenuation results also identify potential melt volumes at a depth of approximately 3500 and

$1537500 \mathrm{~m}$ below the caldera (De Siena et al., 2010). The models of Trasatti et al. (2011) suggest

154 that this shallower source is fed by a deep sill, again at approximately $7500 \mathrm{~km}$ in depth.

155 The recent ground deformation, 2012-2013, was modeled using DInSAR and GPS measurements

156 as the result of a sill-like magma intrusion at approximately 3090 meters in depth (D'Auria et al.,

157 2015), while Amoruso et al. (2014b) demonstrated that a deeper source ( $3600 \mathrm{~m})$, combined

158 with the shallower Solfatara hydrothermal source, can explain the continuous GPS (cGPS)

159 displacements since 2011. Both the subsidence period of 1993-1999 and the more recent uplift,

160 2007-2013, were modeled, again using DInSAR data, as the result of activity in an extended

161 source at depths of approximately 1400 to $2000 \mathrm{~m}$ depth (Samsonov et al. 2014b).

162 Here we apply a PCA decomposition technique (Tiampo et al., 2012) and a GA inversion

163 method to the DInSAR MSBAS data of Samsonov et al. (2014) in order to better discriminate

164 between the potential sources at Campi Flegrei.

165

166

167

\section{MSBAS Analysis}


168 The theoretical derivation of the MSBAS technique is described in detail in Samsonov and 169 d'Oreye (2012) and Samsonov et al. (2013). The technique is derived from the original SBAS 170 method proposed in Berardino et al. (2002) and Usai (2003) but incorporates images from 171 different satellites, coverage and look angles in order to produce two-dimensional time series of 172 ground deformation. At least two sets of DInSAR data are needed, one from ascending and the 173 other from descending orbits. The technique, however, efficiently handles a large number of 174 DInSAR data sets to produce results with improved temporal resolution and precision. Basic 175 DInSAR processing is performed outside of the MSBAS software, using either freely available 176 (e.g. ISCEE, GMT5SAR) or commercial (GAMMA, SARscape) packages. Differential 177 interferograms are processed, filtered, unwrapped and geocoded with the processing software 178 and then resampled to a common grid. The final interferograms are in either angular (e.g. radian) 179 or metric (e.g. $\mathrm{cm}$ or $\mathrm{m}$ ) units, preserved during the MSBAS processing. The topographic 180 correction is accomplished by a joint inversion that solves for the two-dimensional displacements 181 and the residual topographic signal (Samsonov et al., 2011). The resulting deformation maps 182 presented in this work were calculated from two decades of SAR measurements from three 183 different SAR sensors (ERS-1/2, ENVISAT and RADARSAT-2). Individual frames are shown 184 in Figure 1.

185 We processed five independent SAR data sets, described in Table 1, with uninterrupted coverage 186 from 1992 through 2013. We applied 2x10 multilooking to four standard beams and 4x5 187 multilooking to one fine beam and independently processed each data set using GAMMA 188 software (Wegmuller and Werner, 1997). All possible interferometric pairs with perpendicular 189 baselines less than $400 \mathrm{~m}$ were computed and the topographic signal was removed using a $90 \mathrm{~m}$ 190 resolution SRTM DEM (Farr and Kobrick, 2000). Orbital refinement to remove residual orbital 
191 ramps was performed and minor interpolation applied to fill gaps in moderately coherent regions.

192 The final interpolated interferograms were geocoded onto a 90x90 m grid.

194 TABLE 1

195

196

197

198

199

200

201

202

203

204

205

206

207

208

209

210

211

212

213
For the time series analysis we limited data to the Naples Bay area and resampled all interferograms to a common grid (Wessel and Smith, 1998). The final interferograms had a resolution of approximately 90x90 m. We selected only those with an average coherence above 0.5 for further processing. Over one thousand highly coherent interferograms then were used in the MSBAS processing, resulting in a time series with 385 time steps. Average error on the vertical displacement is approximately $0.09 \mathrm{~cm}$ and that of the east-west time series is approximately $0.07 \mathrm{~cm}$ (Samsonov et al., 2014b).

The results of the MSBAS processing are presented in Figure 2. Figure 2a shows the vertical change in surface height between the initial and final time steps while Figure $2 \mathrm{~b}$ is the east-west net displacement. The associated displacement time series are shown in Figure $2 \mathrm{c}$ for the location designated with the pink star. They present a more complicated picture than the net subsidence of Figures $2 \mathrm{a}$ and $2 \mathrm{~b}$. The time series show more than $3 \mathrm{~cm} / \mathrm{yr}$ of maximum subsidence (green dot) between 1993 and 199, centered on the caldera. Subsidence continued at a slower rate, interspersed with short periods of uplift, until 2005. Almost continuous uplift began in 2005 and accelerated to approximately $2.5 \mathrm{~cm} / \mathrm{yr}$ between 2008 and 2011. Deformation is ongoing at a rate of $5 \mathrm{~cm} / \mathrm{yr}(2011-2013)$. The large number of time steps and precise measurements are evident in both the vertical and east-west time series (Figure 2c). The pattern 
214 of deformation in Figure 2 is consistent with one or more sources of contraction and expansion

215 located at depth below the caldera.

216 FIGURE 2

217 Figure 3 shows the net surface displacement for two different time periods, 1993 through 1999

218 and 2007 through 2013. The subsidence that occurred between 1993 and 1999 can be seen in

219 Figure 3a, while the corresponding east-west displacement is provided in Figure 3b. Figure 3c

220 presents the uplift period of 2007-2013 and Figure 3d shows the associated east-west

221 displacements.

\section{FIGURE3}

223

\section{PCA Analysis}

225 The Karhunen-Loeve expansion (KLE) method is a linear decomposition technique in which a 226 dynamical system is decomposed into a complete set of orthonormal subspaces. Depending on 227 the specific decomposition, and whether it is used to characterize the variance or correlation in 228 the data, it also has been known as PCA or empirical orthogonal function (EOF) decomposition.

229 The method, in one form or another, has been applied to a number of complex nonlinear systems 230 over the last fifty years, including the ocean-atmosphere interface, turbulence, meteorology, 231 biometrics, statistics, and geophysics (Hotelling, 1933; Fukunaga, 1970; Aubrey and Emery, 232 1983; Preisendorfer, 1988; Savage, 1988; Penland, 1989; Vautard and Ghil, 1989; Posadas et al., 233 1993; Penland and Sardeshmukh, 1995; Holmes et al., 1996; Moghaddam et al., 1998; Tiampo et 234 al., 2002; Dong et al., 2006; Main et al., 2006; Small and Islam, 2007; Smith et al., 2007). 235 Again, Savage (1988) decomposed the deformation at Long Valley caldera into its predominant 236 modes in order to study only the signal that accounted for the greatest percentage of the variance, 
237 the volcanic source below the dome. In addition, he identified the primary error sources in the 238 data using the remaining eigenmodes.

239 In an application of the KLE to historic seismicity data, Tiampo et al. (2002) constructed a 240 correlation operator, $C\left(x_{i}, x_{j}\right)$, for seismic events over time. Subsequently, $C\left(x_{i}, x_{j}\right)$ was

241 decomposed into its orthonormal spatial eigenmodes and associated time series, $a_{j}(t)$. These 242 spatial and temporal pattern states were used to reconstruct the primary modes of the system, 243 with or without noise, and to characterize the underlying dynamics and the physical parameters 244 that control the observable patterns of events. The decomposition implicitly assumes that one is 245 dealing with a process that is both Markov and stationary in time. Anghel et al. (2004) applied a 246 similar methodology to modeled deformation data with the goal of identifying coherent 247 structures and interactions. Tiampo et al. (2004) applied the KLE technique to SCIGN data in 248 order to determine the principal modes of deformation for the southern California fault system, 249 while Dong et al. (2006) applied a similar technique to SCIGN data in order to study the CME. 250 More recently, it has been applied to DInSAR time series studies, primarily for better 251 understanding of volcanic and groundwater changes (Lipovsky, 2011; Rudolph et al., 2013; 252 Chaussard et al., 2014; Remy et al., 2014).

253 As with the EOF technique developed by Preisendorfer (1988) for the atmospheric sciences, the 254 KLE for displacement applications uses those $p$ time series that record the deformation history at 255 particular locations in space. The primary difference is that while an EOF decomposition is 256 based on the covariance matrix, a KLE decomposition is performed on a correlation operator 257 (Fukunaga, 1970). For the study at Campi Flegrei, we employ an EOF operator. 
258 Each time series, $y\left(x_{s}, t_{i}\right)=y_{i}^{s}, s=1, \ldots p$, consists of $n$ time steps, $i=1, \ldots n$. The goal is to

259 construct a time series for each of a large number of locations for a given short period of time.

260 If, for example, the time interval was decimated into units of days, the result could be a time

261 series of 365 time steps for every year of data, with values of position for that location at each

262 time step. These time series are incorporated into a matrix, $\boldsymbol{T}$, consisting of time series of the

263 same measurement for $p$ different locations, i.e.

$$
T=\left[\bar{y}_{1}, \bar{y}_{2}, \ldots \bar{y}_{p}\right]=\left[\begin{array}{cccc}
y_{1}^{1} & y_{1}^{2} & \ldots & y_{1}^{p} \\
y_{2}^{1} & y_{2}^{2} & \ldots & y_{2}^{p} \\
\vdots & \vdots & \ddots & \vdots \\
y_{n}^{1} & y_{n}^{2} & \ldots & y_{n}^{p}
\end{array}\right]
$$

265 For analysis of DInSAR data, the values in the matrix $\boldsymbol{T}$ consist of horizontal or vertical position 266 measurements. The covariance matrix, $S\left(x_{i}, x_{j}\right)$, for these events is formed by multiplying $\mathbf{T}$ by $267 \boldsymbol{T}^{T}$, where $S$ is a $p \times p$ real, symmetric matrix.

268 This equal-time covariance operator, $S\left(x_{i}, x_{j}\right)$, is decomposed into its eigenvalues and 269 eigenvectors in two parts. The first employs the trireduction technique to reduce the matrix $\boldsymbol{S}$ to a 270 symmetric tridiagonal matrix, using a Householder reduction. The second part employs a QL 271 algorithm to find the eigenvalues, $\lambda_{\mathrm{j}}$, and eigenvectors, $e_{j}$, of the tridiagonal matrix (Press, et al., 272 1992). These eigenvectors, or eigenstates, are orthonormal basis vectors arranged in order of 273 decreasing variance that reflect the spatial relationship of events in time. If one divides the 274 corresponding eigenvalues, $\lambda_{\mathrm{j}}$, by the sum of the eigenvalues, the result is that percent of the 275 correlation accounted for by that particular mode. We then reconstruct the time series associated 276 with each location for each eigenstate by projecting the initial data back onto these basis vectors 277 in what is called a PC analysis (Preisendorfer, 1988). These time dependent expansion 
278 coefficients, $a_{j}(t)$, which represent the temporal eigenvectors, are reconstructed by multiplying

279 the original data matrix by the eigenvectors, i.e.

280

$$
a_{j}\left(t_{i}\right)=\vec{e}^{T} \cdot T=\sum_{s=1}^{p} e_{j} y_{i}^{S},
$$

281 where $j, s=1, \ldots p$ and $i=1, \ldots n$. This eigenstate decomposition technique produces the

282 orthonormal spatial eigenmodes for this nonlinear threshold system, $e_{j}$, and the associated

283 principal component time series, $a_{j}(t)$. These principal component time series represent the signal

284 associated with each particular eigenmode over time. For purposes of clarity, the spatial

285 eigenvectors are designated EOF modes and the associated time series are the principal

286 component analysis (PCA) vectors.

287 PCA often is used to filter data through the identification of those modes associated with large

288 percentages of unwanted covariance or those lower modes accounting for random noise

289 (Preisendorfer, 1988; Penland, 1989; Dong et al., 2006). As discussed above, others have

290 applied the technique to investigate spatiotemporally correlated geophysical signals in the

291 position time series. The first few PCs often represent the biggest contributors to the variance of

292 the network residual time series and the higher-order PCs are related to local site effects (Tiampo

293 et al., 2012). Here we decompose the MSBAS time series for Campi Flegrei into the dominant

294 eigenmodes that describe the local source physics.

295 Here we performed two separate analyses. The first is a covariance PCA decomposition of the 296 east-west MSBAS displacement time series and the second is the same analysis on the vertical 297 MSBAS displacement time series. The matrix $\boldsymbol{T}$ consists of the MSBAS time series for each 
298 pixel in the region shown in Figure 1, or 5308 locations. Each time series consists of 385 time

299 steps, and the resulting covariance matrix, $S\left(x_{i}, x_{j}\right)$, has dimension 5308 by 5308.

300 The significant eigenmodes normally are selected by examination of the eigenvalue distribution,

301 shown in Figure 4 (Preisendorfer, 1988; Tiampo et al., 2010). The first three eigenvalue, $\lambda_{\mathrm{j}}$,

302 account for approximately $98 \%$ of the variance in the vertical time series and $95 \%$ of the east-

303 west time series. As a result, the first three EOFS are selected for further analysis.

304 FIGURE4

305 Figure 5 shows the first three EOFs and the associated PCA time series for the MSBAS vertical

306 displacement time series. Note that the spatial eigenmodes, EOF1, EOF2 and EOF3, represent

307 the amplitude of the signal that is accounted for at each point. The value at each location is then

308 multiplied by the associated PCA time series in order to derive the actual time history attributed

309 to each eigenmode at each location (Equation 2, above). In general, blue pixels are correlated

310 with each other and anticorrelated with red pixels.

\section{FIGURE5}

312 EOF1 (Figure 5a) appears to be directly related to the central source expected to lie below the

313 caldera and the associated PCA time series (Figure 5b) is similar to that for the original MSBAS

314 time series of Figure 2. PCA2 (Figure 5d) shows a predominant linear trend that appears to

315 represent the relationship between the Solfatara hydrothermal activity and a longer wavelength

316 signal encompassing the larger caldera footprint (Figure 5c). EOF3 (Figure 5e) also presents a

317 longer wavelength signal, potentially related to tropospheric error in the images. The associated

318 PCA time series (Figure 5f) is noisy and supports the conclusion that the two earlier modes 
319 account for most of the signal in the data, despite the fact that the third mode might be

320 considered significant from Figure 4.

321 Figure 6 shows the first three EOFs and the associated PCA time series for the MSBAS east-west

322 displacement time series. Note that these three eigenmodes do not necessarily represent the

323 same activity seen in those recovered for the vertical displacements (Figure 5). However, the

324 time series in PCA1 (Figure 6b) corresponds closely to that of the first time series in Figure 5,

325 once the opposite signs are taken into account, suggesting a similar source process. Again, the

326 deformation pattern in EOF1 (Figure 6a) is similar to that expected from a volcanic source

327 located directly below the caldera. EOF2 and EOF3 (Figure 6c and Figure 6e) are less

328 conclusive. Figure $6 \mathrm{f}$ is likely a correction to Figure $6 \mathrm{~d}$. However, the relatively sudden onset of

329 new signal in 1997 suggests that some portion of the signal is related to the volcanic activity

330 itself.

331 FIGURE6

332 EOF3 (Figure 6e) has a similar, but not identical pattern to that seen in EOF2. The strong signal

333 seen on the western peninsula is likely a result of tropospheric noise. In addition, we again

334 observe a strong signal in 1997 in PCA3 (Figure 6f), a pulse of activity that tapers off but

335 remains observable through 2013. It should be noted that an EOF analysis is a linear

336 decomposition of what are inherently nonlinear processes (Preisendorfer, 1988). The result is

337 often a mixture of signals, particularly in the lower, shorter wavelength signals.

338 Figures 7 and 8 show the time series at the three locations shown by green triangles in Figure 3,

339 obtained by summing EOF1, EOF2 and EOF3 in consecutive order (Equation 2, above). Figure

3407 shows the vertical displacement. As expected, the vertical displacement at location c is very 
341 similar to that seen in Figure 2c. However, location b, closer to the anticipated location of the

342 central source is dominated by the linear subsidence that initiated in 2007 . That signal dies away

343 at location a and it appears to be dominated by the secondary uplift signal again associated with

344 the primary source below the volcano.

345 FIGURE7

346 Given that we observe what appears to be only two separately resolvable signals in the PCA

347 results, we inverted for two separate sources below the caldera, using a GA inversion technique

348 and simple pressure sources.

\section{5. GA Inversion}

350 In order to invert for the various combinations of the three PCA modes shown above, we

351 employed a GA inversion technique as outlined in (Tiampo et al., 2004). Briefly, geophysical

352 inverse problems generally involve employing large quantities of measured data, in conjunction

353 with an efficient computational algorithm that explores the model space to find the global

354 minimum associated with the optimal model parameters. In a GA, the parameters to be inverted

355 for are coded as genes, and a large population of potential solutions for these genes is searched

356 for the optimal solution. The basic structure of the GA code used here is modified from

357 Michalewicz (1992). The process begins by representing the model to be optimized as a real-

358 value string. Starting with an initial range of models, these algorithms progressively modify the

359 solution by incorporating the evolutionary behavior of biological systems. The fitness of each

360 solution is measured by a quantitative, objective function, the fitness function, FV. Next, the

361 fittest members of each population are combined using probabilistic transition rules to form a

362 new offspring population. Copying strings according to their fitness values means that strings 
363 with a better value of fitness have a higher probability of contributing one or more offspring in

364 the next generation. This procedure is repeated through a large number of generations until the

365 best solution is obtained, based on the fitness measure (Michalewicz, 1992). Those members of

366 the population with a fitness value greater than the average fitness of the population will increase

367 in number exponentially, accelerating the convergence of the inversion process (Holland, 1975;

368 Goldberg, 1989).

369 In this study we employ the GA to invert only for the vertical displacements for two respective

370 time periods, 1993-1997 (subsidence) and 2007-2013 (uplift), using combinations of EOF1,

371 EOF2 and EOF3 from Figures 5 and 6. A GA inversion can be very time consuming,

372 particularly given the large number of points available in the DInSAR analysis, the vertical

373 deformation alone was selected for the inversion. Given the high quality of the vertical

374 deformation from the DInSAR analysis, it was sufficient for the inversion process alone. In

375 addition, there was no independent data set such as local continuous GPS available to use as an

376 independent check on the model, we did not include the east-west data in the inversion. That

377 allowed us to use the east-west deformation as independent confirmation of the model quality.

378 We assume that the source models are a combination of either one or two simple Mogi pressure

379 sources with either positive or negative pressures for both time periods. Here the vertical and

380 radial components of displacement in a half-space are defined as:

$381 U_{z}=\frac{3 \Delta V d}{4 \pi R^{3 / 2}}$

382 and

$383 U_{r}=\frac{3 \Delta V r}{4 \pi R^{3 / 2}}$. 
Here $U_{z}$ and $U_{r}$ are the vertical and radial displacement, respectively, $d$ is the depth to the source, 385

$R$ is the radial distance to a point on the surface, and $\Delta V$ is the change in volume of the source, 386

here converted to the change in radius, $r$ (Mogi, 1958).

387 The GA inversion solved for the $\mathrm{x}$ and $\mathrm{y}$ location of each source, in UTM coordinates, the radius 388 of the spherical pressure source, $r$, and the depth to each sphere, $d$. The initial search range of 389 parameters for the GA was the spatial extent of the original InSAR images (Figure 2), $r$ values 390 between 20 and $200 \mathrm{~m}$, and depths, $d$, of 1000 to $14000 \mathrm{~m}$ below the surface.

391 The inversion results for six different cases are shown in Table 2. The first case inverts EOF1 392 alone for the time period 2007-2013 for one positive source, two positive sources and two 393 sources, one of which is negative and another which is positive. The second case inverts for 394 EOF1 alone for the time period 1993-1999 for one negative source, two negative sources and 395 two sources, one of which is negative and another which is positive. The third case inverts the 396 sum of EOF1 and EOF2, 2007-2013, for the same three different source options as in Case 1. 397 The fourth case inverts the sum of EOF1 and EOF2, 1993-1999, for the same three different 398 source options as in Case 2. The fifth case inverts the sum of EOF1, EOF2 and EOF3, 2007399 2013, for the same three different source options as in Case 1. The sixth case inverts the sum of 400 EOF1, EOF2 and EOF3, 1993-1999, for the same three different source options as in Case 2. It 401 should be noted that a number of other configurations, both for individual and summed EOF 402 modes and for different source types, were tested as well, but none provided better solutions than 403 those presented in Table 2.

\section{6. Results}

Table 2 shows the time periods chosen for inversion analysis and the resulting parameters for the 407 associated inflation or deflation ( $\mathrm{x}$ and y location, $d$ and $\Delta V$ ). Also provided are the root-mean- 
square (RMS) between the forward model produced by the best solution for each case and the

409 actual data seen in Figure 3, and the associated reduced chi-square value. Here the RMS value is

410 estimated using the error values for each of the 5308 locations provided in the Supplementary

411 Material of Samsonov et al., (2008).

412 The results shown in Table 2 demonstrate that the addition of a second source of the same

413 polarity to the inversion does not improve the RMS. In each of those cases, the GA attempts to

414 minimize the size of that second source while either moving it to the same location as the first

415 source or as deep as possible in the medium. On the other hand, the addition of a second source

416 of opposite polarity always significantly improves the RMS of the solution.

417 Table 2 also shows that the RMS significantly improves with the addition of both EOF2 and

418 EOF3 to EOF1. The best solution for the 2007-2003 time period uses the sum of modes EOF1,

419 EOF2 and EOF3 and results in a shallower, positive source at approximately $3400 \mathrm{~m}$ in depth

420 and deeper, negative source at approximately $7624 \mathrm{~m}$ in depth. The best solution for the 1993-

4211999 time period uses the sum of modes EOF1, EOF2 and EOF3 and results in a shallower,

422 negative source at approximately $2750 \mathrm{~m}$ in depth and deeper, negative source at approximately

$4238014 \mathrm{~m}$ in depth.

424 Figures 8 through 13 present the modelled results and residuals for the six different cases. We

425 omitted results for two sources with the same polarity because of the lack of increase in fitness

426 associated with those solutions. Figure 8 shows the forward model and residuals for the 1993-

4271999 inversion of EOF1 alone, with both one negative source (Figures 8a and 8b) and for two

428 sources of opposite polarity (Figures $8 \mathrm{c}$ and $8 \mathrm{~d}$ ). The residuals are calculated as the difference

429 between the forward model from the best fit inversion for that decomposition and the original

430 MSBAS results for that time period. Figure 9 is for the same time period, 1993-1999, and the 
431 same two cases, one source (Figures 9a and 9b) and two sources (Figures 9c and 9d). However,

432 here the forward model is the result of the inversion of the summation of PCA modes EOF1 and

433 EOF2. Figure 10 also represents the 1993-1999 time period and the same two cases, but the

434 forward model is the result of the inversion of the summation of modes EOF1, EOF2 and EOF3.

435 Note that the addition of EOF3 relocates the second source from the north of the caldera to south,

436 similar to the results of Amoruso et al. (2015).

437 FIGURE8

438 FIGURE9

439 FIGURE10

440 Figure 11 presents the forward model results residuals for the 2007-2013 inversion of EOF1

441 alone, with both one positive source (Figures 11a and 11b) and for two sources of opposite

442 polarity (Figures 11c and 11d). Figure 12 also shows the results for the 2007-2013 time period

443 and the same two cases, but here the forward model is the result of the inversion of the

444 summation of modes EOF1 and EOF2. Figure 13 also represents the period 2007-2013 and the

445 same two cases, but here the forward model is the result of the inversion of the summation of

446 modes EOF1, EOF2 and EOF3. Here all three inversions place the second source in the south of

447 the caldera. The final model suggests that both sources are further south than expected and

448 minimize the residuals from the Solfatara region.

449 FIGURE11

450 FIGURE12

$451 \quad$ FIGURE13 
452 Displacements in the east-west direction were modeled in order to assess how well the source

453 models agreed with the complete displacement field. Figure 14 presents the results from the

454 inversion of the summation of modes EOF1, EOF2 and EOF3 for both time periods. Figure 14a

455 shows the modelled east-west displacements for the two source model derived for 1993-1999, as

456 given in Figure 10. Figure 14b shows the residuals between the model of Figure 14a and the

457 actual displacements. Figure $14 \mathrm{c}$ are the modelled east-west displacements for the two source

458 model of Figure 13, the time period 2007-2013. Figure 14d presents the residuals between

459 model shown in Figure 14c and actual the displacements. The results for both models are in

460 good agreement with the actual data, although the displacements associated with the subsidence

461 model (Figures 14a and 14b), 1993-1999, suggest that the modeled displacements are slightly

462 underfit by the model. The wavelength of the residual signal suggests that is the difference is

463 contained in the shallow source.

464 FIGURE 14

465

466

467

468 In this work we applied, for the first time, a PCA decomposition analysis to the advanced

469 MSBAS DInSAR time series of ground deformation in the Campi Flegrei caldera. The MSBAS

470 time series incorporate ERS-1/2, ENVISAT and RADARSAT-2 data and result in nearly twenty

471 years of data, with uninterrupted temporal coverage for 2003-2013. The PCA analysis produces

472 three significant eigenmodes for both the vertical and east-west time series. These time series

473 were inverted using a GA technique for simple Mogi pressure sources and a variety of cases.

474 The fit to the actual data increases progressively with the addition of each mode, suggesting that

475 each contains important information related to the source mechanisms. The best fit occurs for an

476 inversion that sums all three modes (EOF1, EOF2 and EOF3) and for two sources with opposite 
477 polarity, for both the period of subsidence (1993-1999) and the period of uplift (2007-2013). In

478 the first case, a shallower source is deflating while a deeper source inflates; in the second case, a

479 shallower source is inflating while the deeper source deflates. The time series for EOF2 and

480 EOF3 suggest that a sharp pulse in activity occurred between 1997 and 2002, potentially

481 indicating that the dynamics of the system changed significantly. This hypothesis is supported

482 by a similar uplift signal seen in levelling data from Amoroso et al. (2014a), at the same time that 483 the $\mathrm{CO} 2 / \mathrm{H} 2 \mathrm{O}$ ratio in local fumaroles starts to increase, potentially as a result of an increased

484 contribution of the magmatic component (Chiodini et al., 2012). It has been suggested that this 485 change was driven by magma fed from a deeper magma chamber, such as that found in our 486 inversion for the sum of modes EOF1, EOF2 and EOF3 (Zollo et al., 2008; Amoroso et al., 487 2014a; Di Vito et al., 2016). Incorporation of all three modes is necessary to significantly 488 improve the fit and model the two sources together.

489 Past work, using various combinations of geodetic data, including leveling, trilateration, GPS, 490 gravity and DInSAR, have found that the shallower source can be fit better using different 491 geometries and some combination of shallower hydrothermal sources (see, e.g. De Natale et al. 492 1991; Battaglia et al., 2006; De Natale et al., 2006; Gottsmann et al., 2005, 2006; Amoruso et al., 493 2008; Trasatti et al., 2011; Chiodini et al., 2012; Amoruso et al., 2014a,b; Samsonov et al., 494 2014b; Trasatti et al., 2015; Di Vito et al., 2016). Here we found that two simple, spherical 495 sources of opposite polarity, one deeper and the second shallow, provided an adequate fit to the 496 data without resorting to sills or spheroidal magma chambers.

497 The final models for both periods place the shallower source at between 2750 and $3400 \mathrm{~m}$ below 498 the caldera, at either the upper or lower edge of the gas bearing rock layer (Figure 1). The 499 deeper source is more stable, at 7600 to 8000 meters in depth, also as suggested by earlier work 
500 (Trasatti et al., 2011, 2015). Expansion of the existing SAR data set using new satellite data (e.g.

501 Sentinel-1a and $1 \mathrm{~b}$ ) will help to better characterize these sources with time.

502 This study provides evidence for the effectiveness of PCA in denoising large geophysical data

503 sets, including DInSAR data. Dense time series are critical to the process and, as a result,

504 suggests that MSBAS time series will be of increasing importance in the accurate and reliable

505 estimation of natural and anthropogenic hazards.

506

507 Acknowledgements

508 We thank the Canadian Space Agency for providing RADARSAT-2 data and the European 509 Space Agency for providing ERS and ENVISAT. We also would like to thank three anonymous 510 reviewers for their thorough reviews. Figures were plotted with GMT. The work of PG was 511 supported by a Banting Postdoctoral Fellowship. The work of KFT was supported by an NSERC 512 Discovery Grant and CIRES, University of Colorado Boulder. This work also was supported by 513 the AQUARISK Spanish project and the EU MED-SUV project. 


\section{References}

Anghel, M., Y. Ben-Zion, and R.R. Martinez (2004), Dynamical system analysis and forecasting of deformation produced by an earthquake fault, Pure and Applied Geophysics, 161, doi:10.1007/s00024-004-2547-9.

Amoruso, A., Crescentini, L., and Sabbetta, I. (2014a), Paired deformation sources of the Campi Flegrei caldera (Italy) required by recent (1980-2010) deformation history, J. Geophys. Res, 119, 858-879, doi:10.1002/2013JB010392.

Amoruso, A., L. Crescentini, I. Sabbetta, P. De Martino, F. Obrizzo, and U. Tammaro (2014b), Clues to the cause of the 2011-2013 Campi Flegrei caldera unrest, Italy, from cGPS data, Geophys. Res. Lett., 41, 3081-3088, doi:10.1002/2014GL059539.

Amoruso, A., L. Crescentini, R. Scarpa, R. Bilham, A. T. Linde, and I. S. Sacks (2015), Abrupt magma chambercontraction and microseismicity at Campi Flegrei, Italy: Cause and effect determined from strainmeters and tiltmeters, J. Geophys. Res., 120, 5467-5478, doi:10.1002/2015JB012085.

Arienzo, I., Moretti, R., Civietta, L., Orsi, G., and Papale, P. (2010), The feeding system of Agnano-Monte Spina eruption (Campi Flegrei, Italy): Dragging the past into present activity and future scenarios, Chemical Geology, 270, 135-147.

Aubrey, D. G., and K. O. Emery, (1983), Eigenanalysis of recent United States sea levels, Cont. Shelf Res., 2, 21-33, 1983.

Battaglia, M., C. Troise, F. Obrizzo, F. Pingue, and G. De Natale (2006), Evidence for fluid migration as the source of deformation at Campi Flegrei Caldera (Italy), Geophys. Res. Lett., 33, L01307, doi:10.1029/2005GL024904.

Berardino, P., Fornaro, G., and Lanari, R. (2002), A new algorithm for surface deformation monitoring based on small baseline differential SAR interferograms. IEEE Trans. Geosc. Rem. Sens., 40, 2375-2383.

Bonafede, M. and Mazzanti, M., (1998), Modelling gravity variations consistent with ground deformation in the Campi Flegrei caldera (Italy), J. Volc. Geotherm. Res., 81:137-157. Caliro, S., Chiodini, G., Moretti, R., Avino, R., Granieri, D., Russo, M., Fiebig, J. (2007). The origin of the fumaroles of La Solfatara (Campi Flegrei, South Italy), Geochim. Cosmochim. Acta, 71: 3040-3055.

Chaussard, E., R. Bürgmann, M. Shirzaei, E. J. Fielding, and B. Baker (2014), Predictability of hydraulic head change and characterization of aquifer-system and fault properties from InSARderived ground deformation, J. Geophys. Res., 119, doi:10.1002/2014JB011266.

Chiodini, G., S. Caliro, C. Cardellini, D. Granieri, R. Avino, A. Baldini, M. Donnini, and C. Minopoli (2010), Long-term variations of the Campi Flegrei, Italy, volcanic system as revealed by the monitoring of hydrothermal activity, J. Geophys. Res., 115, B03205, doi:10.1029/2008JB006258.

Chiodini, G., S. Caliro, P. De Martino, R. Avino, and F. Gherardi (2012), Early signals of new volcanic unrest at Campi Flegrei caldera? Insights from geochemical data and physical simulations, Geology, 40, doi:10.1130/G33251.1.

D'Auria, L., Giudicepietro. F., Martini, M. and Lanari, R. (2012), The 4D imaging of the source of ground deformation at Campi Flegrei caldera (southern Italy), J. of Geophys. Res. 117, B08209, doi:10.1029/2012JB009181.

D’Auria, L., Giudicepietro. F., Aquino, I., Borriello, G., Del Gaudio, C., Lo Bascio, D., Martini, M., Ricciardi, G.P., Ricciolino, P., and Ricco, C. (2011), Repeated fluid-transfer episodes as a 
mechanism for the recent dynamics of Campi Flegrei caldera (1989-2010), J. of Geophys. Res. 116, B04313, doi:10.1029/2010JB007837.

D’Auria, L., Pepe, S., Castaldo, R., Giudicepietro, F., Macedonio, G., Ricciolino, P., Tizzani, P., Casu, F., Lanari, R., Manzo, M., Martini, M., Sansosti, E., Zinno, I. (2015), Magma injection beneath the urban area of Naples: a new mechanism for the 2012-2013 volcanic unrest at Campi Flegrei caldera, Scientific Reports, doi:10.1038/srep13100.

Davis, R. O., A.P.S. Selvadurai (1996), Elasticity and Geomechanics, 201 pp., Cambridge Univ. Press, Cambridge, U. K.

Del Gaudio, C., Aquino I., Ricciardi, G.P., Ricco, C., Scandone, R. (2010), Unrest episodes at Campi Flegrei: A reconstruction of vertical ground movements during 1905-2009, J. Volc.

Geoth. Res., 195, doi:10.1016/j.jvolgeores.2010.05.014.

De Martino, P., U. Tammaro, F. Obrizzo (2014), GPS time series at Campi Flegrei caldera (2000-2013), Ann. Geophys., 57(2), S0213, doi:10.4401/ag-6431.

De Natale, G., F. Pingue, P. Allard, and A. Zollo (1991), Geophysical and geochemical modelling of the 1982-1984 unrest phenomena at Campi Flegrei caldera (southern Italy), $J$. Volcanol. Geotherm. Res., 48, 199-222.

De Natale, G., Troise, C., Pingue, F., Mastrolorenzo G., Pappalardo L., Battaglia M., and Boschi E. (2006), The Campi Flegrei caldera: unrest mechanisms and hazards, in Troise C., De Natale G. \& Kilburn C.R.J. Mechanisms of activity and unrest at large calderas. Geological Society, London, Special Publications, 269:25-45, doi:10.1144/GSL.SP.2006.269.01.03.

De Siena, L., E. Del Pezzo, and F. Bianco (2010), Seismic attenuation imaging of Campi Flegrei: Evidence of gas reservoirs, hydrothermal basins, and feeding systems, J. Geophys. Res., 115, B09312, doi:10.1029/2009JB006938.

Di Vito, M.A., Acocella, V., Aiello, G., Barra, D., Battaglia, M., Carandente, A., Del Gaudio, C., de Vita, S., Ricciardi, G.P., Ricco, C., Scandone, R., and Terrasi, F. (2016), Magma transfer at Campi Flegrei caldera (Italy) before the 1538 AD eruption, Scientific Reports, doi:10.1038/srep32245.

Dong, D., T.A. Herring, and R.A. King (1998), Estimating regional deformation from a combination of space and terrestrial geodetic data, J. Geod., 72, $200-214$.

Dvorak, J.J. and Berrino, G., 1991. Recent ground movements and seismic activity in Campi Flegrei, southern Italy: episodic growth of a resurgent dome, J. Geophys. Res., 96:2309-2323. Farr, T., and Kobrick, M. (2000), Shuttle Radar Topography Mission produces a wealth of data, EOS Transactions, $A G U, 81: 583-585$.

Fernández, J., Tiampo, K.F. and Rundle, J.B., 2001. Viscoelastic displacement and gravity changes due to point magmatic intrusions in a gravitational layered solid Earth, Geophys. J. Int., 146:155-170.

Ferretti, A., Prati, C., Rocca, F. (2001), Permanent scatterers in SAR interferometry. IEEE Trans. Geosc. Rem. Sens., 39, 8-20.

Fukunaga, K. (1970), Introduction to Statistical Pattern Recognition, Academic, San Diego, Calif. Goldberg, D.E. (1989), Genetic Algorithms in Search, Optimization, and Machine Learning (Addison Wesley, Reading, MA).

Gottsmann, J., Camacho, A., Fernández, J., and Tiampo, K.F. (2006), Spatio-temporal variations in vertical gravity gradients at the Campi Flegrei volcano (Italy): A case for source multiplicity during unrest? Geophysical Journal International, 167, doi:10.1111/j.1365-246X.2006.03157.x, 1089-1096. 
Gottsmann, J., Folch, A. \& Rymer, H. (2005), Unrest at Campi Flegrei: a contribution to the magmatic vs. hydrothermal debate from inverse and finite element modeling, J. Geophys. Res., 111, B07203, doi:10.1029/2005JB003745.

Holland, J.H. (1975), Adaptation in Natural and Artificial Systems (MIT Press, Cambridge, MA).

Holmes, P., J. L. Lumley, and G. Berkooz, (1996), Turbulence, Coherent Structures, Dynamical Systems and Symmetry, Cambridge Univ. Press, New York.

Hotelling, H. (1933), Analysis of a complex of statistical variables into principal components, $J$. Educ. Psych., 24, 417-520.

Hooper, A. (2008), A multi-temporal InSAR method incorporating both persistent scatterer and small baseline approaches. Geophysical Research Letters, 35:16302.

Isaia, R., Marianelli, P., and Sbrana, A. (2009), Caldera unrest prior intense volcanism in Campi Flegrei (Italy) at 4.0 ka B.P.: Implications for caldera dynamics and future eruptive scenarios, Geophysical Research Letters, 36:L21303.

Main, I.G., L. Li, K. J. Heffer, O. Papasouliotis, and T. Leonard (2006), Long-range, criticalpoint dynamics in oil field flow rate data, Geophys. Res. Lett., 33, L18308, doi:10.1029/2006GL027357.

Masterlark, T. (2007), Magma intrusion and deformation predictions: Sensitivities to the Mogi assumptions, J. Geophys. Res., 112, B06419, doi:10.1029/2006JB004860.

Michalewicz, Z. (1992), Genetic Algorithms + Data Structures = Evolution Programs. SpringerVerlag, New York, NY.

Moghaddam, B., W. Wahid, and A. Pentland, Beyond eigenfaces: Probabilistic matching for face recognition, paper presented at Third IEEE International Conference on Automatic Face and Gesture Recognition, Nara, Japan, 14- 16 April 1998.

Mogi, K. (1958), Relations between the eruptions of various volcanoes and the deformations of the ground surfaces around them, Bull. Earth. Res. Inst. Tokyo, 36, 99-134.

Moretti, R., Arienzo, I., Civetta, L., Orsi, G., Papale, P. (2013), Multiple magma degassing sources at an explosive volcano, Earth Plan. Sci. Lett., 367: 95-104.

Mormone, A., Piochi, M., Belltreccia, F., De Astis, G., Moretti, R., Della Ventura, G., Cavallo, A., Mangiacapra, A. (2011), A CO 2 -rich magma source beneath the Phlegraean Volcanic District (Southern Italy): Evidence from a melt inclusion study, Chemical Geology, 287:66-80. Orsi, G., Di Vito, M.A., Isaia, R., 2004. Volcanic hazard assessment at the restless Campi Flegrei caldera. Bull. Volc. 66, 514-530.

Penland, C. (1989), Random forcing and forecasting using principal oscillation pattern analysis, Mon. Weather Rev., 117, 2165 - 2185.

Penland, C., and P. D. Sardeshmukh (1995), The optimal growth of tropical sea surface temperature anomalies, J. Clim., 8, 1999 - 2024.

Posadas, A.M., F. Vidal, F. DeMiguel, G. Alguacil, J. Pena, J.M. Ibanez, and J. Morales (1993), Spatial-temporal analysis of a seismic series using the principal components method - the Antequera series, Spain, 1989, J. Geophys. Res., 98, 1923-1932.

Preisendorfer, R. W. (1988), Principle Component Analysis in Meteorology and Oceanography, Elsevier Sci., New York.

Press, W. H., B. P. Flannery, S. A. Teukolsky, and W. T. Vettering, (1992), Numerical Recipes in $\mathrm{C}$, 2nd ed., Cambridge Univ. Press, New York.

Remy, D., J. L. Froger, H. Perfettini, S. Bonvalot, G. Gabalda, F. Albino, V. Cayol, D. Legrand, and M. Saint Blanquat (2014), Persistent uplift of the Lazufre volcanic complex (Central Andes): 
New insights from PCAIM inversion of InSAR time series and GPS data, Geochem. Geophys. Geosyst., 15, 3591-3611, doi:10.1002/2014GC005370. Rudolph, M. L.,M. Shirzaei, M. Manga, and Y. Fukushima (2013), Evolution and future of the Lusi mud eruption inferred from ground deformation, Geophys. Res. Lett., 40, 1089-1092,

657 doi:10.1002/grl.50189.

658 Rosi, M., A. Sbrana, C. Principe (1983), The Phlegraean Fields; structural evolution, volcanic history and eruptive mechanisms, J. Volcanol. Geotherm. Res., 17, 273-288. Saleh, B. (2002), Underground deformation measurements using new quarts instruments, paper presented at the 95th Annual CIG Geomatics Conference, Can. Inst. of Geomatics, Ottawa, Ont., Canada, 8-23 July.

663 Samsonov, S. (2010), Topographic correction for ALOS PALSAR interferometry. IEEE

664 Transactions on Geoscience and Remote Sensing, 48:3020-3027.

665

666

667

668

669

670

671

672

673

674

675

676

677

678

679

680

681

682

683

684

685

686

687

688

689

690

691

692

693

694

695

696

697

698
Samsonov, S. and d'Oreye, N. (2012), Multidimensional time series analysis of ground deformation from multiple InSAR data sets applied to Virunga Volcanic Province, Geophysical Journal International, 191(3):1095-1108, doi:10.1111/j.1365-246X.2012.05669.x.

Samsonov, S., d'Oreye, N., González, P., Tiampo, K., Ertolahti, L, Clague, J.J. (2014a), Rapidly accelerating subsidence in the Greater Vancouver region from two decades of ERS-ENVISATRADARSAT-2 DInSAR measurements, Rem. Sens. Env., doi:10.1016/j.rse.2013.12.017. Samsonov, S., d'Oreye, N., and Smets, B. (2013), Ground deformation associated with postmining activity at the French-German border revealed by novel InSAR time series method, International Journal of Applied Earth Observation and Geoinformation, 23:142-154.

Samsonov, S.V., Tiampo, K.F., Camacho, A., Fernández, J., González, P.J. (2014b), Spatiotemporal analysis and interpretation of 1993-2013 ground deformation at Campi Flegrei, Italy, observed by advanced DInSAR, Geophys. Res. Lett., doi:10.1002/2014GL061307. Samsonov, S., van der Koij, M., K. Tiampo, (2011). A simultaneous inversion for deformation rates and topographic errors of DInSAR data utilizing linear least square inversion technique. Computers and Geosciences, 37:1083-1091.

Savage, J. C. (1988), Principal component analysis of geodetically measured deformation in Long Valley caldera, eastern California, 1983 - 1987, J. Geophys. Res., 93, 13,297 - 13,305. Small, D., and S. Islam (2007), Decadal variability in the frequency of fall precipitation over the United States, Geophys. Res. Lett.,, 34, L02404, doi:10.1029/2006GL028610.

Smith, E.G.C., T.D. Williams, and D.J. Darby (2007), Principal component analysis and modeling of the subsidence of the shoreline of Lake Taupo, New Zealand, 1983-1999: Evidence for dewatering of a magmatic intrusion?, J. Geophys. Res., 112, B08406, doi:10.1029/2006JB004652.

Tiampo, K., Fernández, J., Jentzsch, G., Charco, M., and J. Rundle, (2004), Inverting for the parameters of a volcanic source using a genetic algorithm and a model for magmatic intrusion in elastic-gravitational layered earth models. Computers and Geosciences, 30 (9), 985-1001. Tiampo, K.F., Mazzotti, S., T. James (2012), Analysis of GPS measurements in eastern Canada using principal component analysis, Pure and Applied Geophysics, doi:10.1007/s00024-0110420-1.

Tiampo, K.F., Rundle, J.B., Gross, S.J., McGinnis, S., W. Klein (2002), Eigenpatterns in southern California seismicity, J. Geophys. Res, 107, 2354, doi:10.1029/2001JB000562. Tiampo, K.F., J.B. Rundle, W. Klein, Y. Ben-Zion, S. McGinnis, (2004), Using eigenpattern analysis to constrain seasonal signals in southern California, Pure and Applied Geophysics, 161: 1991. doi:10.1007/s00024-004-2545-y. 
Trasatti, E., M. Bonafede, C. Ferrari, C. Giunchi, and G. Berrino (2011), On deformation sources in volcanic areas: Modeling the Campi Flegrei (Italy) 1982-84 unrest, Earth Plan. Sci. Lett., 306, 175-185, doi:10.1016/j.eps1.2011.03.033.

Trasatti, E., M. Polcari, M. Bonafede, and S. Stramondo (2015), Geodetic constraints to the source mechanism of the 2011-2013 unrest at Campi Flegrei (Italy) caldera, Geophys. Res. Lett., 42, 3847-3854, doi:10.1002/2015GL063621.

Troiano, A., M. G. Di Giuseppe, Z. Petrillo, C. Troise, and G. De Natale (2011), Ground deformation at calderas driven by fluid injection: Modelling unrest episodes at Campi Flegrei (Italy), Geophys. J. Int., 187, 833-847, doi:10.1111/j.1365-246X.2011.05149.x. Troise, C., De Natale, G., Pingue, F., Obrizzo, F., De Martino, P., Tammaro, U., Boschi, E., (2007). Renewed ground uplift at Campi Flegrei caldera (Italy): New insight on magmatic processes and forecast, Geophysical Research Letters 34, L03301. doi:10.1029/2006GL028545. Usai. S. (2003), A least squares database approach for SAR interferometric data. IEEE Trans. Geosc. Rem. Sens., 41:753760.

Vautard, R., and M. Ghil (1989), Singular spectrum analysis in nonlinear dynamics, with applications to paleodynamic time series, Physica D, 35, 395 - 424.

Wegmuller, U. and Werner, C. (1997), Gamma SAR processor and interferometry software, in Third ERS Symposium on Space at the service of our Environment, Florence, Italy. Wessel, P. and Smith, W. (1998), New, improved version of the generic mapping tools released, EOS Transactions, AGU, 79:579.

Zerbini, S., Raicich, F., Richter, B., Gorini, V., M. Errico (2010), Hydrological signals in height and gravity in northeastern Italy inferred from principal components analysis, J. Geodynamics, doi:10.1016/j.jog.2009.11.001.

Zollo, A., N. Maercklin, M. Vassallo, D. Dello Iacono, J. Virieux, and P. Gasparini (2008), Seismic reflections reveal a massive melt layer feeding Campi Flegrei caldera, Geophys. Res. Lett., 35, L12306, doi:10.1029/2008GL034242. 

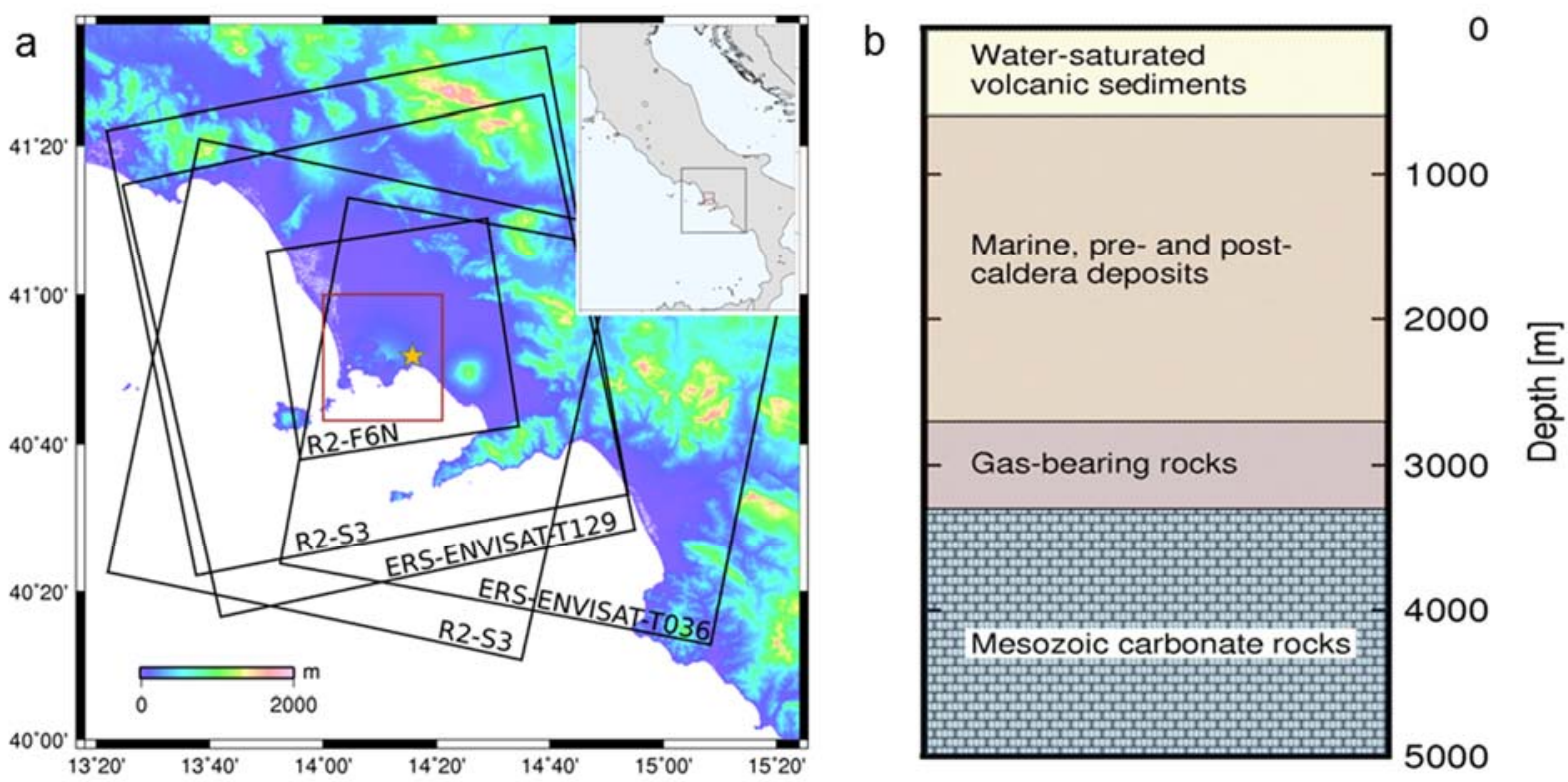

729 Figure 1: (a) Map of the Naples region, Italy, with Campi Flegrei caldera outlined in the red box 730 (city of Naples, orange star). Black boxes identify frames for each of the ERS-ENVISAT (T129 731 and T036) and RADARSAT-2 (S3, both ascending and descending, and F6N) radar image 732 frames. (b) Simplified geologic cross section of the caldera structure. 

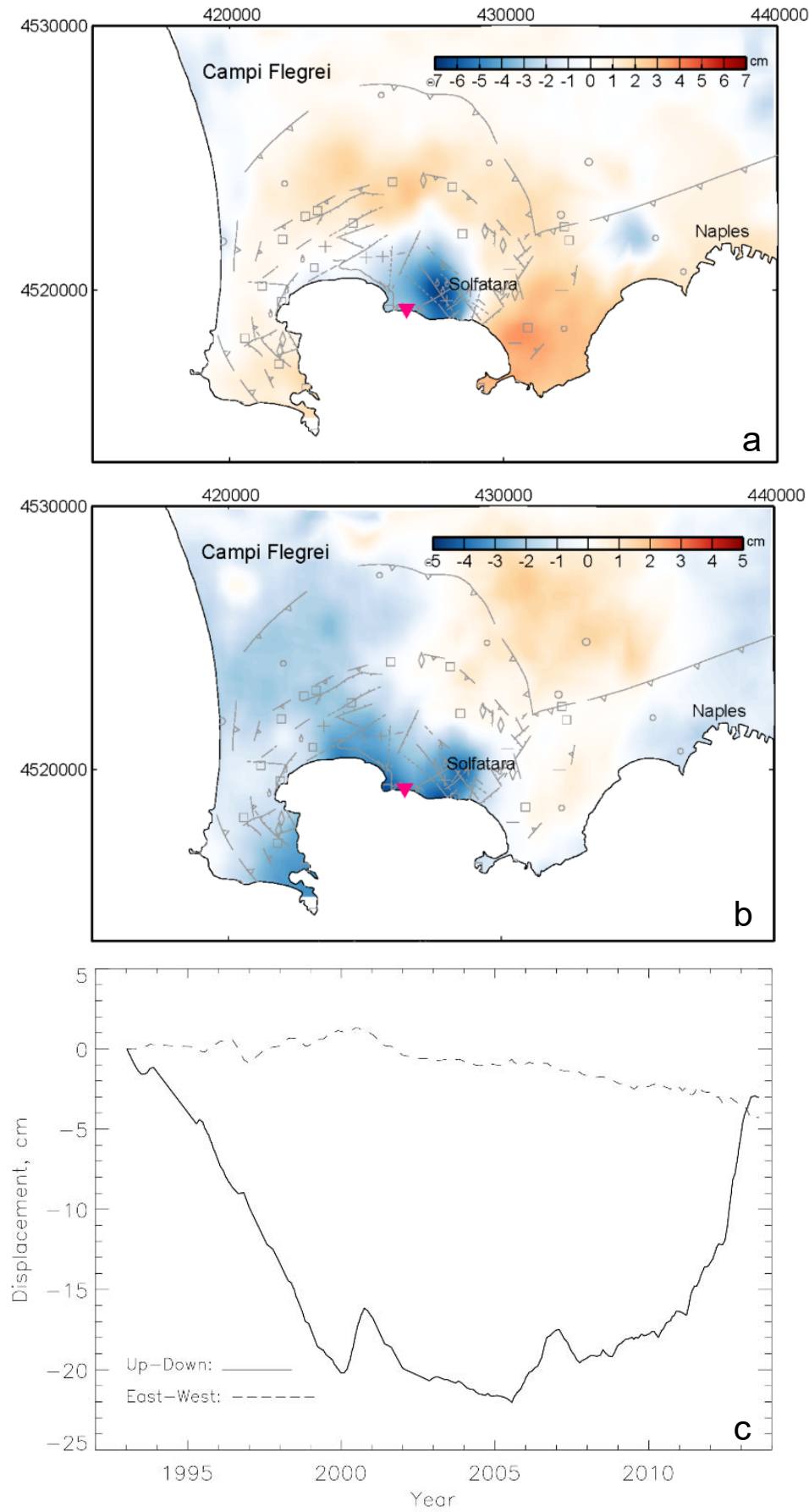

Figure 2: MSBAS results, 1992-2013, for the images outlined in Figure 1 (see Table 1 for details). a) Vertical component of deformation, 1992-2013; b) east-west component of deformation, 1992-2013; c) time series of vertical and east-west components identified in (a) and (b) by pink triangle. Modified from Samsonov et al., 2014. 

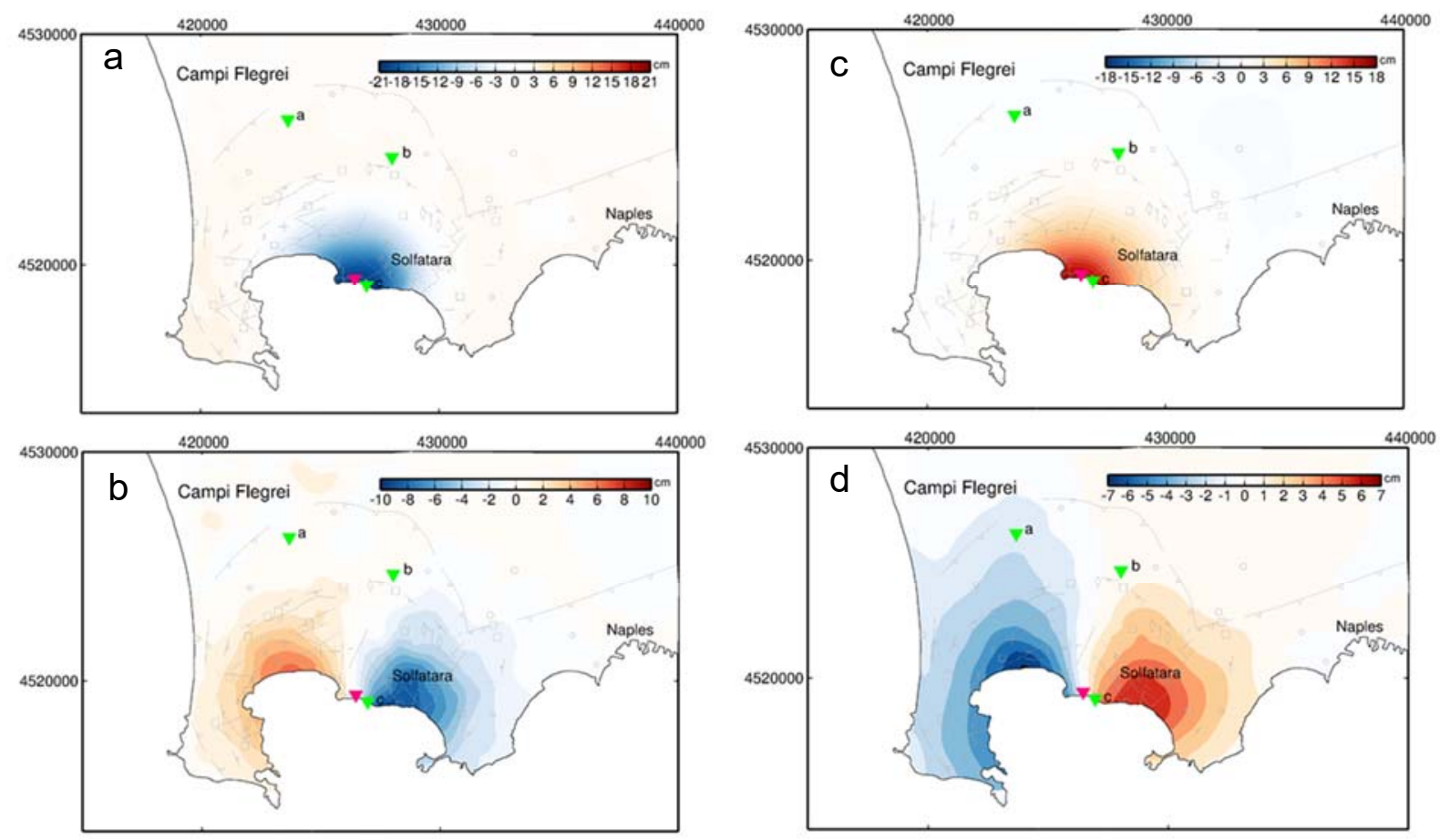

Figure 3: Net surface deformation for two time periods chosen from the time series of Figure 1. a) Vertical surface displacement, 1993-1999 and b) east-west surface displacement, 1993-1999. c) Vertical surface displacement, 2007-2013 and c) east-west surface displacement, 2007-2013.

782 Pink triangle is as shown in Figure 2; green triangles identify location of time series in Figures 7 783 and 8. 
788

789

a

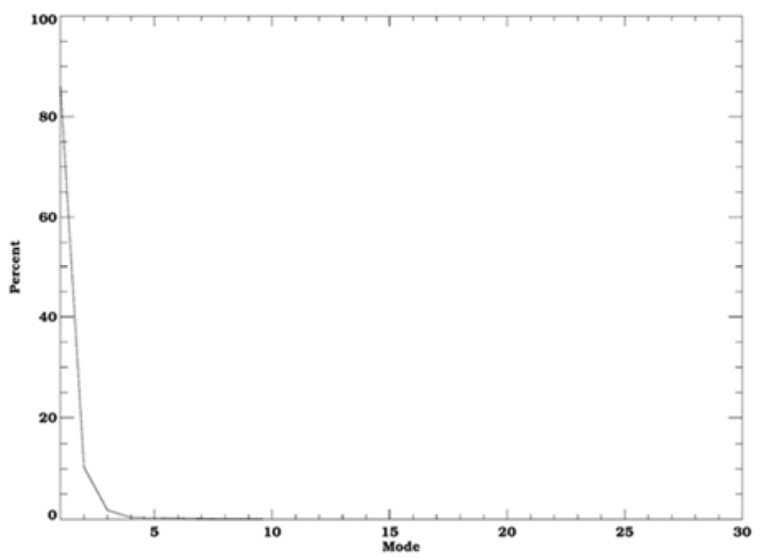

b

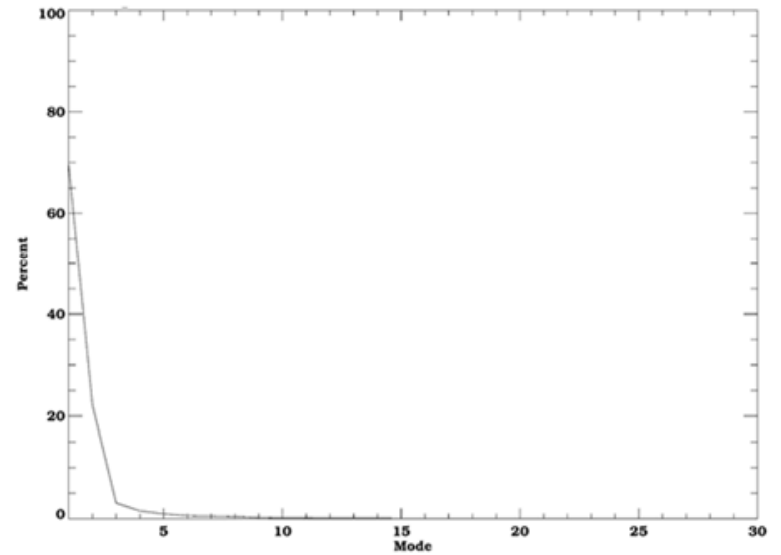

Figure 4: Eigenvalue plots showng the percentage of variance accounted for by each

792 eigenvector mode for the decomposition of MSBAS time series of surface displacement in a) the 793 vertical direction and $b$ ) the east-west direction. 

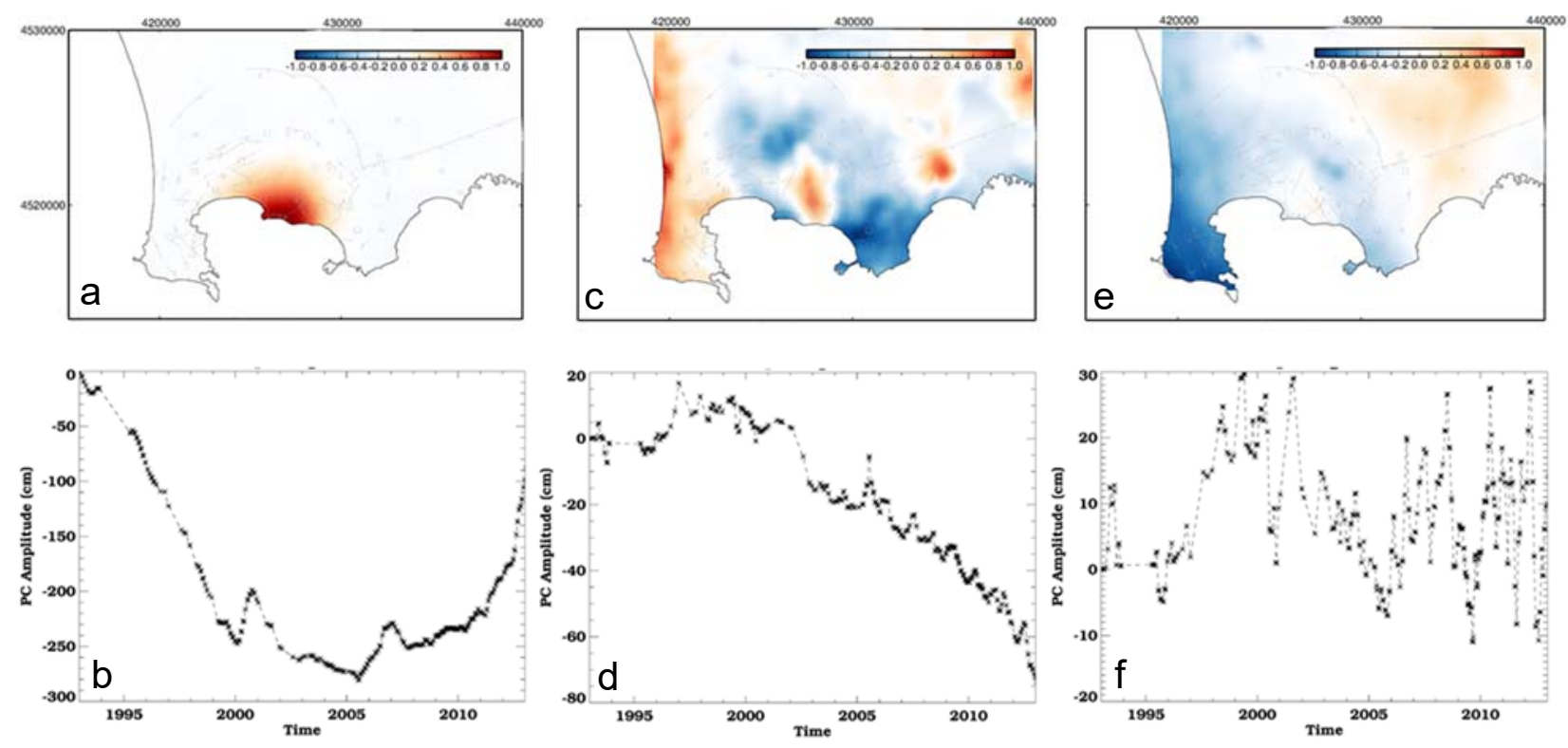

794

795

796

797

798

799

800
Figure 5: First three eigenmodes for vertical displacement, 1993-2013. a) First spatial eigenmode (EOF1); b) principal component time seres associated with EOF1 (PCA1); c) second spatial eigenmode (EOF2); d) principal component time seres associated with EOF2 (PCA2); e) third spatial eigenmode (EOF3); f) principal component time seres associated with EOF3 (PCA3). Here blue is anticorrelated with red, EOF plots a, c, and e. 

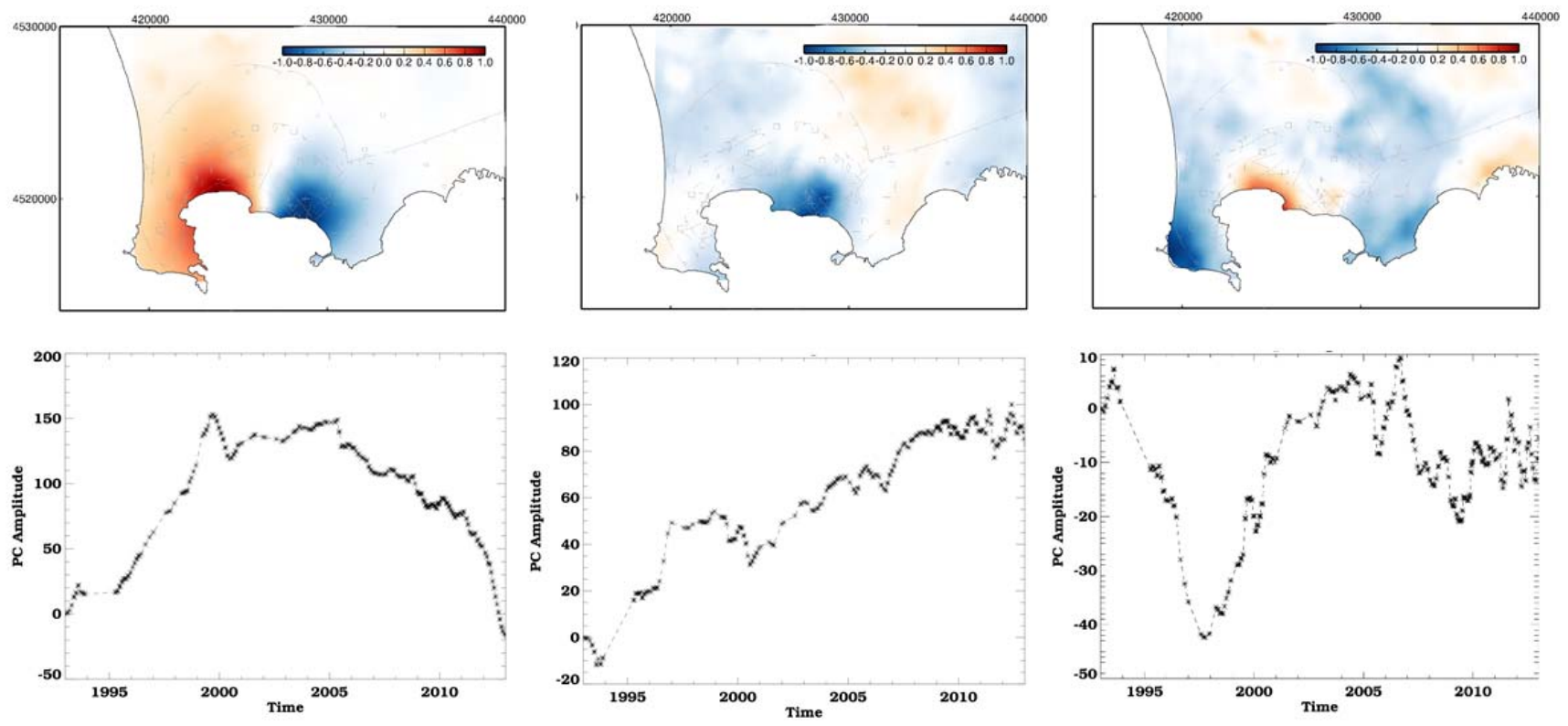

806

807

808

809

810

811

812

Figure 6: First three eigenmodes for east-west displacement, 1993-2013. a) First spatial eigenmode (EOF1); b) principal component time seres associated with EOF1 (PCA1); c) second spatial eigenmode (EOF2); d) principal component time seres associated with EOF2 (PCA2); e) third spatial eigenmode (EOF3); f) principal component time seres associated with EOF3 (PCA3). Here blue is anticorrelated with red, EOF plots a, c, and e. 

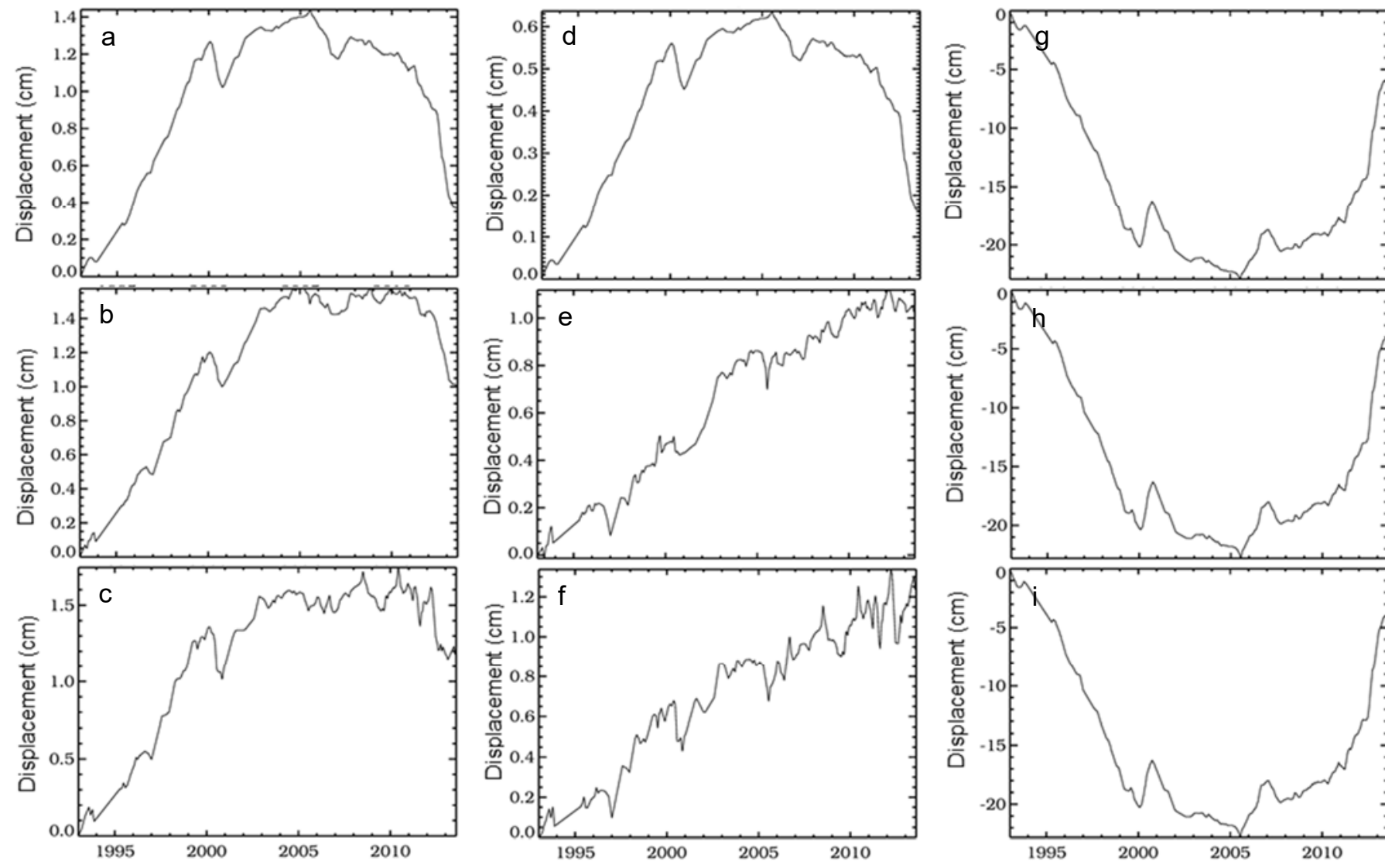

813 Figure 7: Time series of vertical displacement for combinations of the first three EOFS at the

814 locations shown by green triangles in Figure 3. Vertical displacement at location a, Figure 3 is

815 shown for a) EOF1, b) EOF1 and EOF2, summed, and c) EOF1, EOF2 and EOF3, summed.

816 Vertical displacement at location b, Figure 3 is shown for d) EOF1, e) EOF1 and EOF2,

817 summed, and f) EOF1, EOF2 and EOF3, summed. Vertical displacement at location c, Figure 3

818 is shown for g) EOF1, h) EOF1 and EOF2, summed; and i) EOF1, EOF2 and EOF3, summed. 

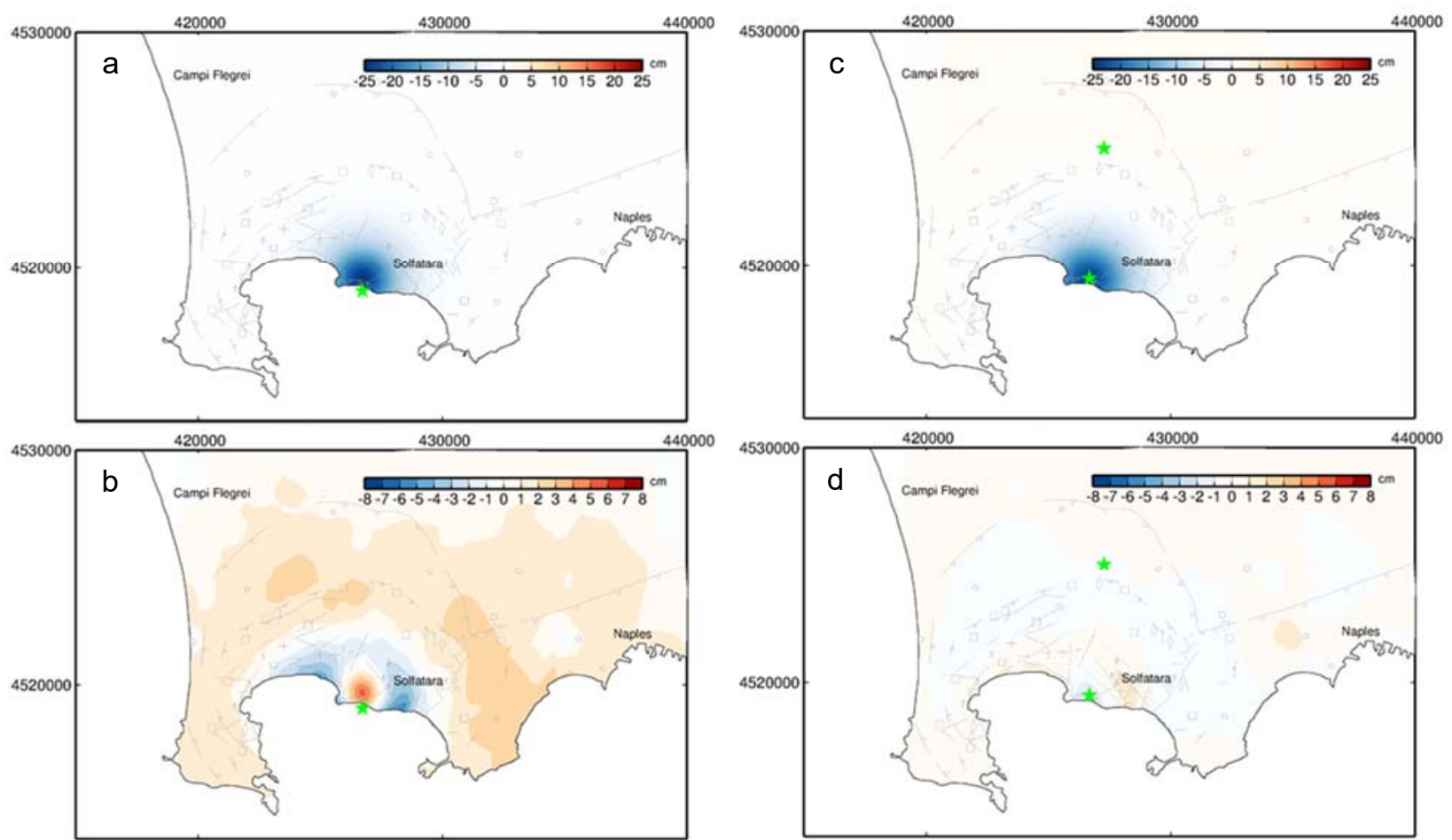

Figure 8: Modelled displacements and residuals in the vertical direction inverted for EOF1 for the time period 1993-1999 (subsidence). a) Displacements for a single source model, location shown by green star, at a depth of 1665 meters below the surface (mbs); b) residuals between model shown in (a) and actual displacements (Figure 2); c) displacements for a two source model, locations shown by green stars, at depths of 2069 (south, negative) and 13802 (north, positive) mbs; d) residuals between model shown in (c) and actual displacements (Figure 2). All displacements and residuals in $\mathrm{cm}$; source details are given in Table 2. 

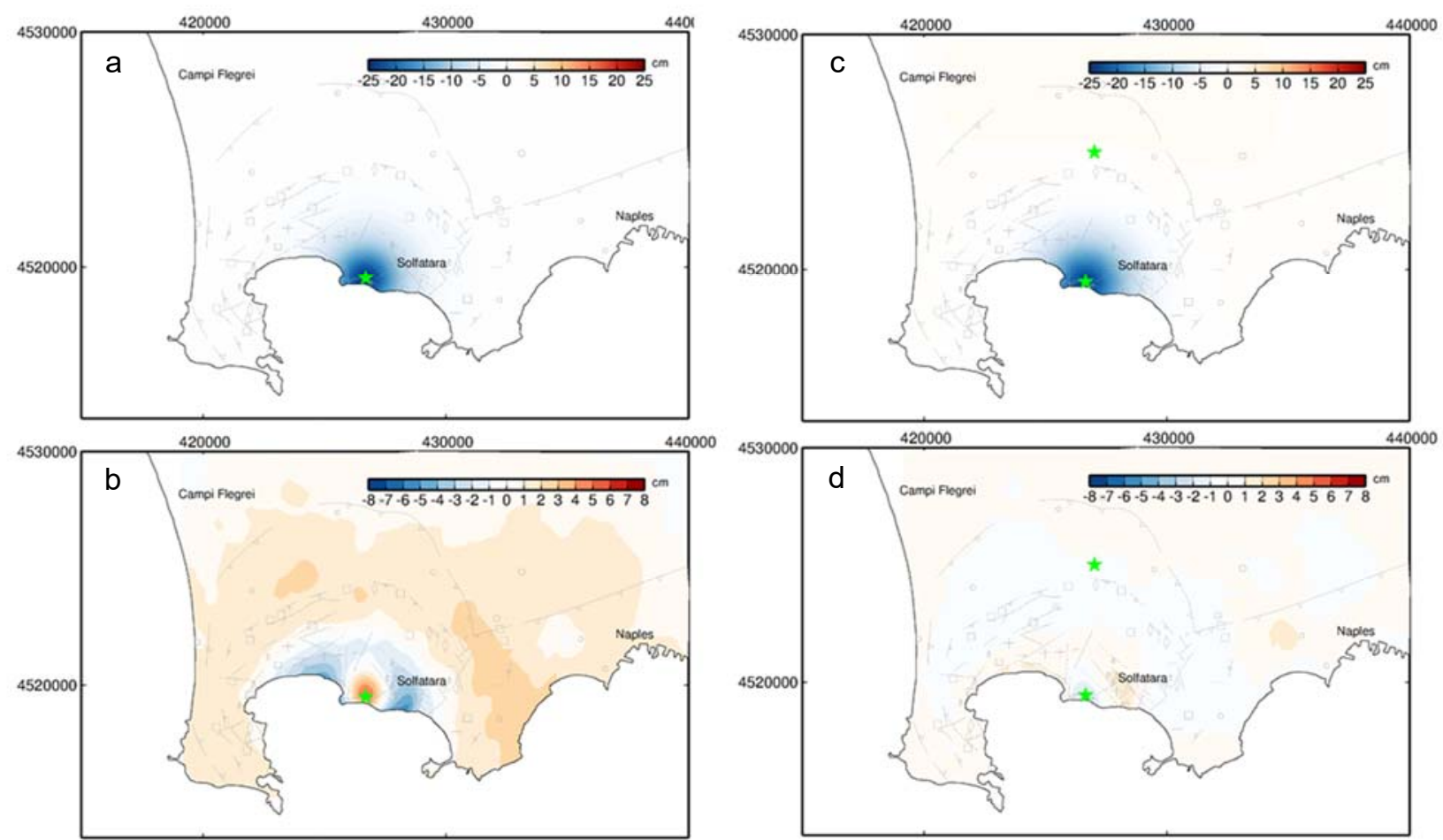

831

832

833

834

835

836

837

838

Figure 9: Modelled displacements and residuals in the vertical direction inverted for EOF12 for the time period 1993-1999 (subsidence). a) Displacements for a single source model, location shown by green star, at a depth of $1690 \mathrm{mbs}$; b) residuals between model shown in (a) and actual displacements (Figure 2); c) displacements for a two source model, locations shown by green stars, at depths of 2102 (south, negative) and 14834 (north, positive) mbs; d) residuals between model shown in (c) and actual displacements (Figure 2). All displacements and residuals in cm; source details are given in Table 2. 

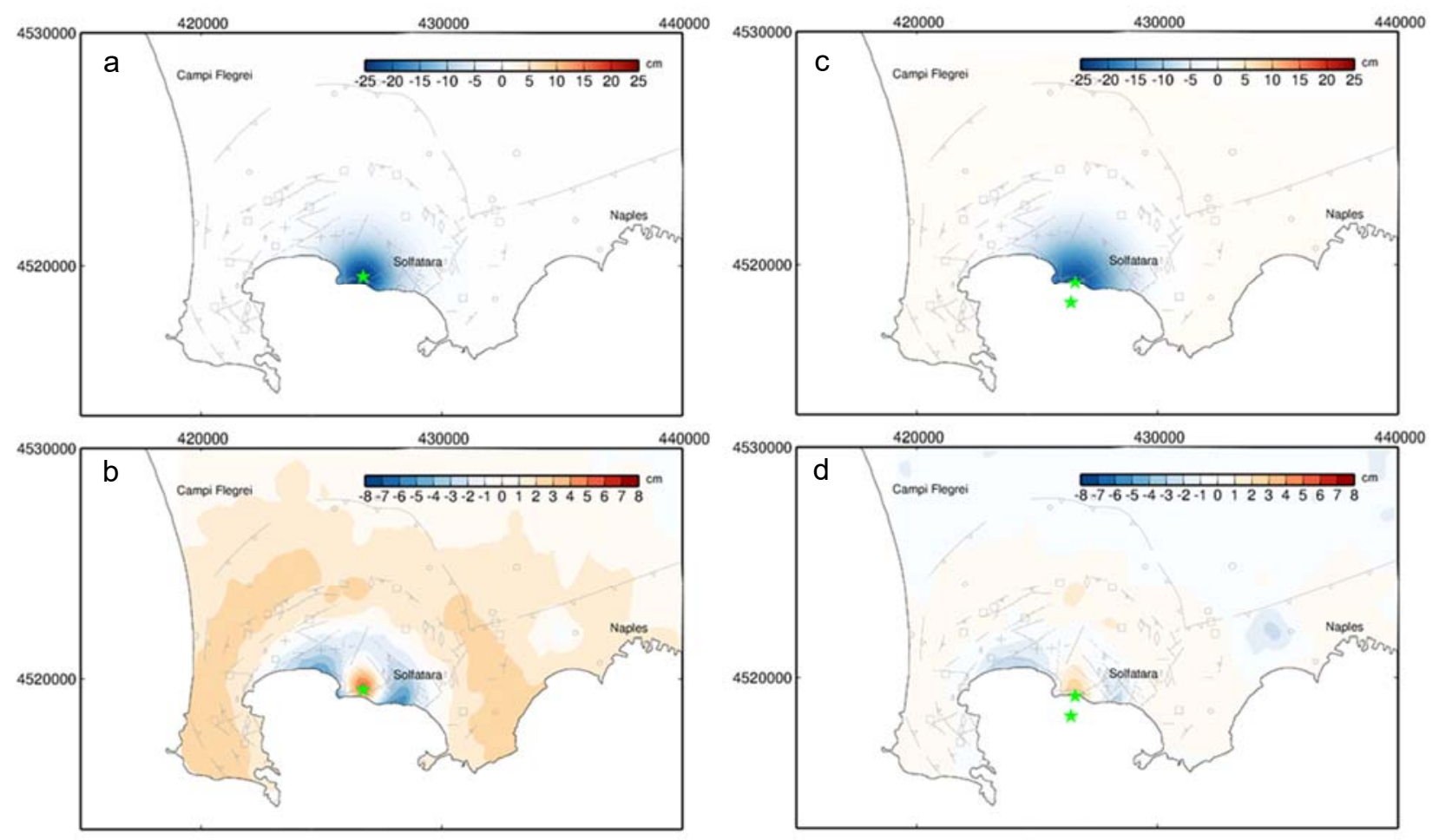

Figure 10: Modelled displacements and residuals in the vertical direction inverted for EOF123 for the time period 1993-1999 (subsidence). a) Displacements for a single source model,

841 location shown by green star, at a depth of $1623 \mathrm{mbs}$; b) residuals between model shown in (a)

842 and actual displacements (Figure 2); c) displacements for a two source model, locations shown

843 by green stars, at depths of 2749 (south, negative) and 8014 (north, positive) mbs; d) residuals

844 between model shown in (c) and actual displacements (Figure 2). All displacements and

845 residuals in cm; source details are given in Table 2. 

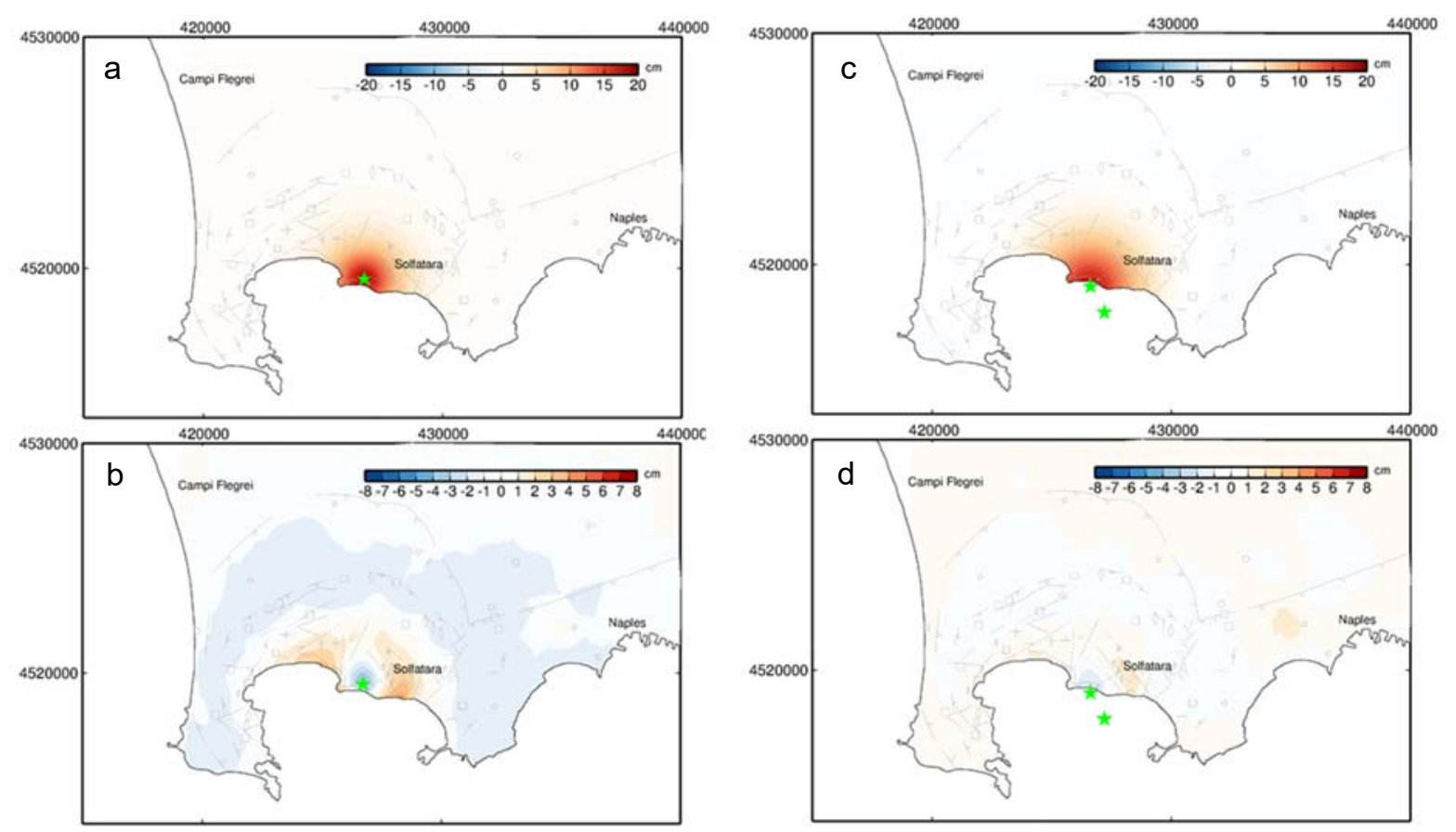

847 Figure 11: Modelled displacements and residuals in the vertical direction inverted for EOF1 for 848 the time period 2007-2013 (uplift). a) Displacements for a single source model, location shown 849 by green star, at a depth of $1671 \mathrm{mbs}$; b) residuals between model shown in (a) and actual 850 displacements (Figure 2); c) displacements for a two source model, locations shown by green 851 stars, at depths of 2892 (south, positive) and 8454 (north, negative) mbs; d) residuals between 852 model shown in (c) and actual displacements (Figure 2). All displacements and residuals in cm; 853 source details are given in Table 2. 


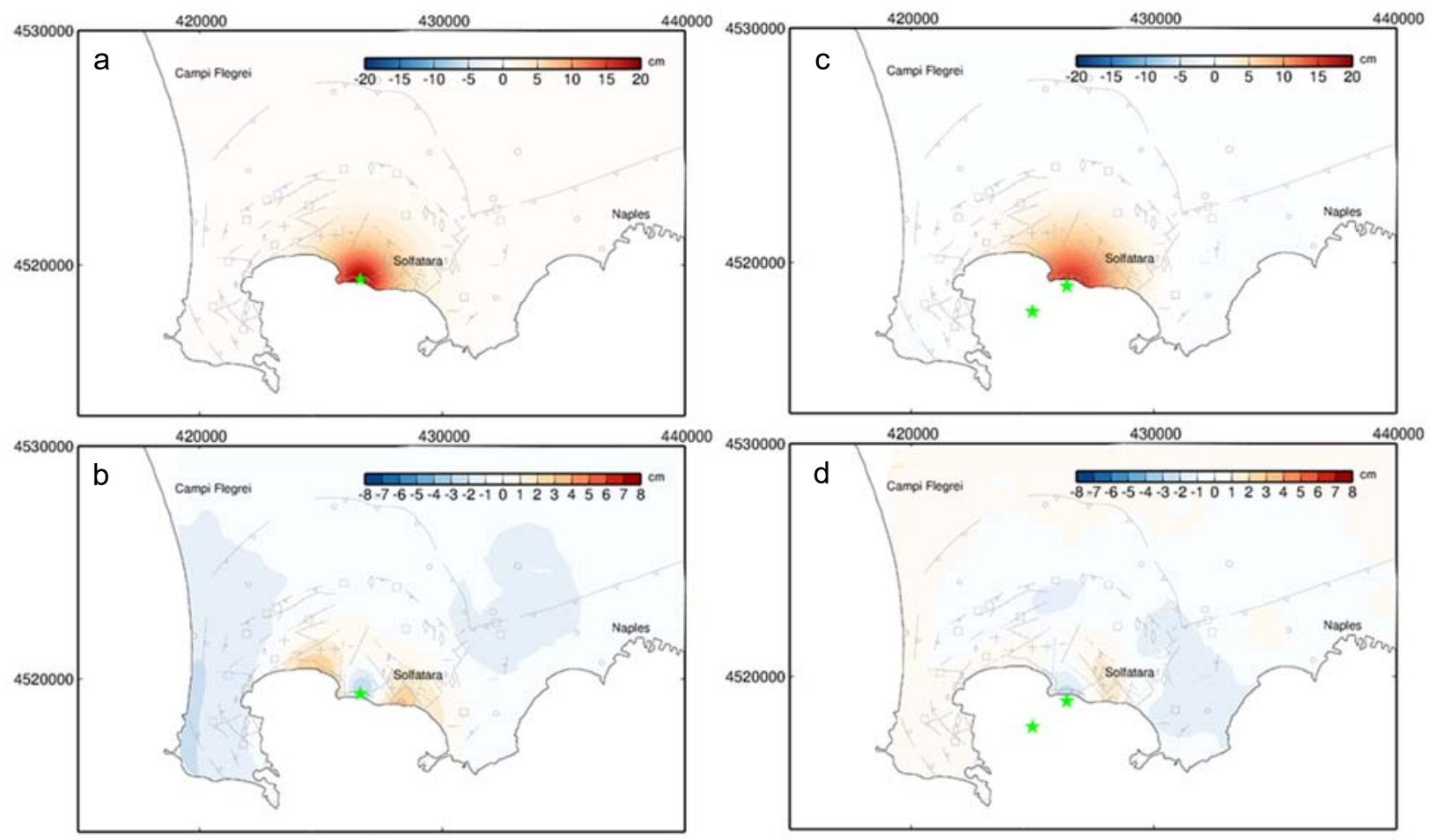

855 Figure 12: Modelled displacements and residuals in the vertical direction inverted for EOF12

856 for the time period 2007-2013 (uplift). a) Displacements for a single source model, location

857 shown by green star, at a depth of $1810 \mathrm{mbs}$; b) residuals between model shown in (a) and actual

858 displacements (Figure 2); c) displacements for a two source model, locations shown by green

859 stars, at depths of 2818 (south, positive) and 9340 (north, negative) mbs; d) residuals between

860 model shown in (c) and actual displacements (Figure 2). All displacements and residuals in cm;

861 source details are given in Table 2. 


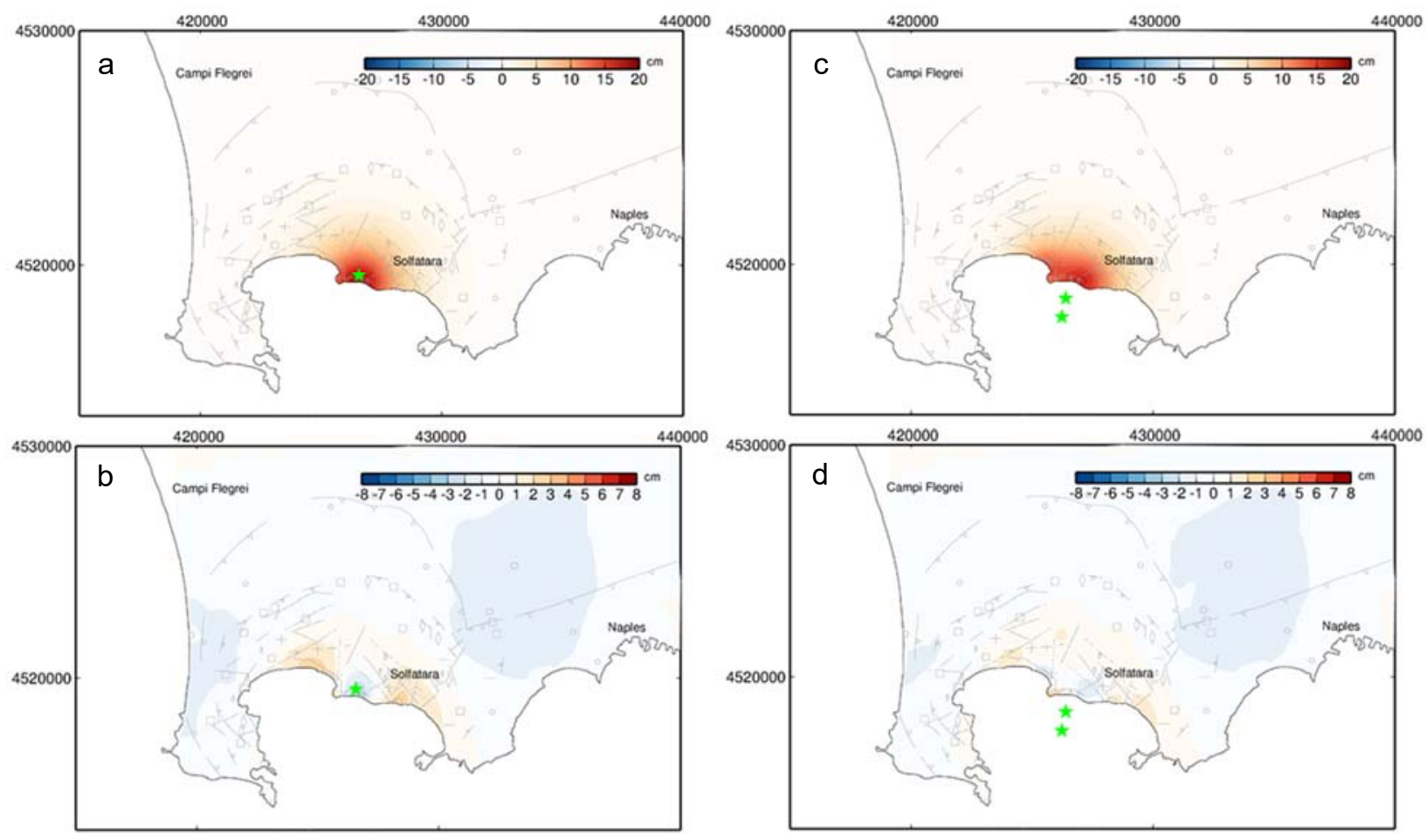

863 Figure 13: Modelled displacements and residuals in the vertical direction inverted for EOF123

864 for the time period 2007-2013 (uplift). a) Displacements for a single source model, location

865 shown by green star, at a depth of $1987 \mathrm{mbs}$; b) residuals between model shown in (a) and actual

866 displacements (Figure 2); c) displacements for a two source model, locations shown by green

867 stars, at depths of 3402 (south, positive) and 7624 (north, negative) mbs; d) residuals between

868 model shown in (c) and actual displacements (Figure 2). All displacements and residuals in cm;

869 source details are given in Table 2. 

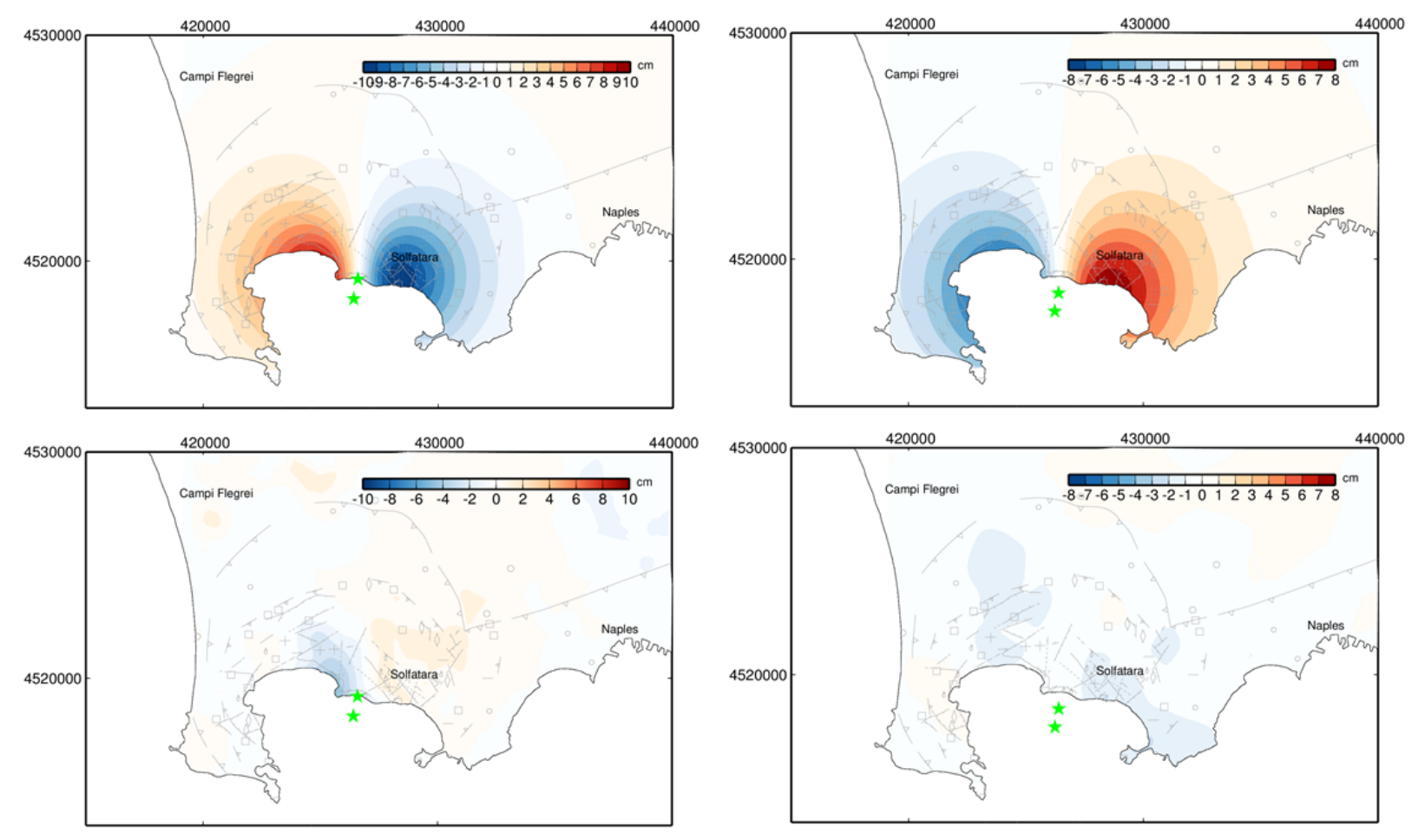

871 Figure 14: Modelled displacements and residuals in the east-west direction for the best fit two 872 source model, using EOF123, as given in Table 2. a) Modelled displacements for a two source 873 model, location shown by green star, for the 1993-1999 (subsidence); b) residuals between 874 model shown in (a) and actual displacements (Figure 2b); c) displacements for the two source 875 model, locations shown by green stars, for the time period 2007-2013 (uplift); d) residuals 876 between model shown in (c) and actual displacements (Figure 2b). All displacements and 877 residuals in $\mathrm{cm}$. 
880 Table 1: Seven DInSAR data sets providing continuous coverage from 1993 through 2013 used 881 in this study. Included are incidence angle $\varphi$ (degrees), azimuth angle $\theta$ (degrees), the number of 882 available SLC SAR images, $N$, and the number of computed highly coherent interferograms, $M$.

883

884 DInSAR data set

Orbit Coverage period $\begin{array}{lllll}\theta & \varphi & N & M\end{array}$

885 ERS, Track 129

$\begin{array}{llllll}\text { asc } \quad 19930110-20080917 & 344.1 & 23.2 & 90 & 215\end{array}$

886 ERS, Track 036

887 ENVISAT, Track 129

dsc $\quad \begin{array}{llllll}19920608-20081225 & 194.1 & 23.2 & 84 & 164\end{array}$

888 ENVISAT, Track 036

asc $\quad 20021113-20091216 \quad 344.0 \quad 22.8 \quad 46 \quad 120$

889 R2, S3

dsc $\quad 20030605-20101021 \quad 195.9 \quad 22.8 \quad 60 \quad 158$

890 R2, S3

asc $\quad 20090119-20130802 \quad 348.7 \quad 35.1 \quad 42 \quad 166$

891 R2, F6

dsc $\quad \begin{array}{llllll}20081227-20130803 & 190.4 & 35.1 & 53 & 290\end{array}$

892

893 Total $M=1271$

894 Combined coverage: 19930110-20130803

895 Total number of unique time steps $=385$ ( 48 repeated by different sensors)

896 
900 Table 2: GA inversion results for different combinations of EOF modes for each time period, 901 1993-1999 (9399) and 2007-2013 (0713), and multiple source types. Here 'Opposing' refers to 902 two sources with opposite polarity.

903

\begin{tabular}{|c|c|c|c|c|c|c|c|c|c|c|}
\hline $\begin{array}{l}\text { Mode } \\
\text { Time period } \\
\text { Source type } \\
\end{array}$ & $\begin{array}{l}\text { RMS } \\
(\mathrm{cm})\end{array}$ & $\begin{array}{c}\text { Reduced } \\
\text { chi-square }\end{array}$ & $\begin{array}{c}\text { x-loc1 } \\
\text { (m UTM) }\end{array}$ & $\begin{array}{c}\mathrm{y} \text {-loc1 } \\
\text { (m UTM) }\end{array}$ & $\begin{array}{c}\text { depth1 } \\
(\mathrm{m})\end{array}$ & $\begin{array}{c}\Delta V \\
\left(m^{\wedge} 3\right) \\
\end{array}$ & $\begin{array}{c}\text { x-loc2 } \\
\text { (m UTM) }\end{array}$ & $\begin{array}{c}\mathrm{y}-\mathrm{loc} 2 \\
\text { (m UTM) }\end{array}$ & $\begin{array}{c}\text { depth2 } \\
(\mathrm{m}) \\
\end{array}$ & $\begin{array}{c}\Delta V \\
\left(m^{\wedge} 3\right) \\
\end{array}$ \\
\hline $\begin{array}{l}\text { EOF1 } \\
0713\end{array}$ & & & & & & & & & & \\
\hline One source & 0.88 & 76 & 426727.7 & 4519507 & 1671 & 498850 & $\mathrm{~N} / \mathrm{A}$ & N/A & $\mathrm{N} / \mathrm{A}$ & N/A \\
\hline Two source & 0.88 & 76 & 426726.4 & 4519510 & 1679 & 495814 & 429994.7 & 4534989 & 12839 & 4188.8 \\
\hline $\begin{array}{l}\text { Opposing } \\
9399\end{array}$ & 0.68 & 45 & 426623.9 & 4519007 & 2892 & 1831470 & 427207.2 & 4517885 & 8454 & -3764178.3 \\
\hline One source & 1.51 & 251 & 426729.2 & 4519518 & 1665 & -681793 & N/A & $\mathrm{N} / \mathrm{A}$ & $\mathrm{N} / \mathrm{A}$ & N/A \\
\hline Two source & 1.52 & 257 & 426733.5 & 4519523 & 1675 & -685546 & 429850.4 & 4534926 & 14947 & -65449.8 \\
\hline $\begin{array}{l}\text { Opposing } \\
\text { EOF12 } \\
0713\end{array}$ & 1.01 & 112 & 426679.0 & 4519452 & 2069 & -1062394 & 427273.6 & 4525027 & 13802 & 3434913.4 \\
\hline One source & 0.81 & 76 & 426628.2 & 4519374 & 1810 & 599211 & N/A & $\mathrm{N} / \mathrm{A}$ & $\mathrm{N} / \mathrm{A}$ & $\mathrm{N} / \mathrm{A}$ \\
\hline Two source & 0.81 & 79 & 425512.9 & 4519377 & 1805 & 599211 & 429906.2 & 4534986 & 14969 & 66238.3 \\
\hline $\begin{array}{l}\text { Opposing } \\
9399\end{array}$ & 0.51 & 25 & 426417.4 & 4518949 & 2818 & 1683618 & 425000.8 & 4517856 & 9340 & -3380160.2 \\
\hline One source & 1.51 & 255 & 426706.1 & 4519497 & 1690 & -704517 & $\mathrm{~N} / \mathrm{A}$ & N/A & N/A & $\mathrm{N} / \mathrm{A}$ \\
\hline Two source & 1.52 & 259 & 426689.1 & 4519439 & 1690 & -712203 & 429984.1 & 4534950 & 14969 & -69455.8 \\
\hline $\begin{array}{l}\text { Opposing } \\
\text { EOF123 } \\
0713\end{array}$ & 1.00 & 114 & 426656.0 & 4519441 & 2102 & -1087768 & 427021.8 & 4525006 & 14834 & 3822992.5 \\
\hline One source & 0.78 & 82 & 426576.2 & 4519232 & 1987 & 723836 & $\mathrm{~N} / \mathrm{A}$ & $\mathrm{N} / \mathrm{A}$ & $\mathrm{N} / \mathrm{A}$ & $\mathrm{N} / \mathrm{A}$ \\
\hline Two source & 0.80 & 82 & $426572 / 4$ & 4519232 & 2003 & 727741 & 427482.1 & 4510122 & 5055 & 67033.2 \\
\hline $\begin{array}{l}\text { Opposing } \\
9399\end{array}$ & 0.32 & 14 & 426394.7 & 4518504 & 3402 & 2942928 & 426234.9 & 4517698 & 7624 & -4113840.0 \\
\hline One source & 1.51 & 244 & 426733.1 & 4519531 & 1623 & -652261 & N/A & $\mathrm{N} / \mathrm{A}$ & N/A & N/A \\
\hline Two source & 1.51 & 250 & 426733.6 & 4519526 & 1656 & -666918 & 427014.1 & 4510018 & 13897 & -35561.4 \\
\hline Opposing & 0.57 & 43 & 426583.2 & 4519206 & 2749 & -2250847 & 426410.1 & 4518333 & 8014 & 4630734.3 \\
\hline
\end{tabular}

